\title{
El proceso de oligarquización europeo. De la utopía federal a una distopía social y democrática*
}

\author{
The European Oligarchization Process. \\ From the Federal Utopia to a Social and Democratic Dystopia \\ Iñigo Bullain \\ Universidad del País Vasco/Euskal Herriko Unibertsitatea
}

doi: $10.18543 /$ ced-54-2016pp59-98

Sumario: I. Introducción.-II. El horizonte neoliberal de la UE y su crisis de legitimidad.--III. El contexto de la Globalización.--IV. Desconstitucionalización, debilitamiento democrático y gobierno corporativo. 1. Decisionismo ejecutivo. 2. Palidez democrática. 3. Puertas giratorias.-V. Conclusiones y bases para otra Europa.

Resumen: Tras seis décadas de desarrollo la integración europea se ha concretado en una suerte de distopía social y democrática. En un proceso de oligarquización neoliberal que se ha acelerado con la globalización y que ha derivado en la desconstitucionalización y el debilitamiento democrático tanto de las instituciones europeas como de sus Estados Miembros. El coste de eludir la federalización ha sido una crisis de legitimidad sin precedentes. Este texto trata de advertir de que si en lugar de una unión federal, social y democrática la UE prosigue con su deriva neoliberal la integración europea correrá serio peligro, y que recuperar la confianza de la población requiere de un cambio de paradigma que implique que más Europa debe ser también sinónimo de más cohesión social y de más democracia.

Palabras clave: Oligarquización. Neoliberalismo. Globalización. Desconstitucionalización.

Abstract: After six decades european integration has turned into a social and democratic distopia. As a consequence of a neoliberal process acelerated by globalization "oligarchy Europe» has fueled deconstitution and febled democracy in both european institutions and member states. Avoiding a european federation has brought a legitimacy crisis without precedent and to recover the confidence of its population a new social and democratic paradigm will be needed. More Europe should mean aswell more social cohesion and more democracy and new steps are to be made regarding budget and fiscal policies, communication networks, institutional framework and community values.

Keywords: Oligarchy. Neoliberalism. Globalisation. Executive decisionism.

* Recibido el 20 de enero de 2016, aceptado el 8 de febrero de 2016. 


\section{Introducción}

Tras seis décadas de andadura, el sueño de una Europa unida y su proyecto de unos Estados Unidos de Europa se ha ido desvaneciendo. Aunque el futuro de la integración sigue siendo una incógnita, la utopía que inspiró al federalismo europeo de postguerra no ha consolidado aquel sueño sino una suerte de Europa zombi que se mueve a golpe de crisis. Sus tratados, instituciones y representantes afirman que la Unión Europea (UE) profesa valores humanistas y democráticos que persiguen objetivos de bienestar y justicia social, pero en su praxis, la Europa realmente existente, se parece cada vez menos a una Europa social y democrática. La bipolaridad entre su discurso y la política que lleva adelante ha conducido a una suerte de esquizofrenia cognitiva en la que también parecen vivir muchos investigadores y académicos. Recurriendo a argumentos como la singularidad de la integración o el carácter dinámico del proceso, se justifica el ninguneo de los valores y principios democráticos y sociales que encabezan los Tratados ${ }^{1}$. Europa se ha ido transformando en un artefacto neoliberal que desarrolla un experimento postdemocrático. El recurso a la libertad del mercado como paradigma de legitimidad sirve para disimular la oligarquización de la economía y de la política y recuerda a la hipocresía que en su día acompañaba a los discursos sobre igualdad y fraternidad en los países del socialismo realmente existente.

La UE vive una aguda crisis de legitimidad que deriva, de un lado, de que el aumento de poderes a favor de las instituciones europeas no ha venido acompañado de más democracia. Por el contrario, la acumulación y centralización de poderes en instituciones «no mayoritarias» como el Consejo Europeo, el Banco Central, o en órganos «informales» como el Eurogrupo o la Troika han servido para convertir la UE en un instrumento de avanzadilla postdemocrática. Se trata de instituciones cuya composición no depende salvo remotamente de los electores y cuyos titulares no responden por sus decisiones ante el electorado. No se trata de negar, pues resulta incontestable, que en sus seis décadas de andadura la Unión Europea no haya alcanzado con éxito algunos de sus objetivos, como el intercambio de bienes; relativamente, el de servicios, o más intensamente la circulación de capitales entre sus Estados Miembros. O que también ha sido capaz de mantener en su territorio la paz y el respeto de las libertades fundamentales ${ }^{2}$ y que la pacificación de la política europea ha venido acompañada de decenios de prosperidad: los denominados treinta gloriosos. Pero ese pasado eu-

${ }^{1}$ Los valores y objetivos de los artículos 2 y 3 del Tratado de la Unión que han estado en el frontispicio de la integración desde París a Lisboa.

2 Aunque Francia en Argelia, el Reino Unido en Irlanda del Norte o España en Euskadi hayan cometido graves abusos durante años. 
ropeo, tan próximo, ha dado paso a un presente continuo de malestar social y a una perspectiva inquietante para el futuro de las generaciones más jóvenes $^{3}$. Por otro lado, la deslegitimación de la UE también deriva de la perdida de confianza de la población en sus resultados, que ha dejado de ver al proyecto de integración como un instrumento garante de bienestar. No es exagerado afirmar que en Europa el proyecto de integración vive sus horas más oscuras, y que lo que sólo hace poco parecería imposible: el colapso de la Unión, es una posibilidad inquietante.

Este texto va a tratar de ofrecer al lector algunos datos y reflexiones críticas en torno a la integración europea. Para quienes nos hemos interesado por Europa desde hace muchos años y hemos ligado la aventura académica a su estudio, el devenir de la UE no es sólo un tema intelectual. Europa es también una cuestión sentimental. Estas líneas se alejan del euroconformismo dominante pero también, a pesar de su sabor amargo, del euroescepticismo que recurre al viejo paradigma de la vuelta al nacionalismo de Estado. Porque la UE es un experimento histórico inédito y muy complejo que se desarrolla en un marco más amplio, este artículo intenta incorporar al análisis el campo de batalla que denominamos globalización en donde por sus pequeñas dimensiones los Estados-nación europeos no son una alternativa viable. Necesitamos más Europa, pero una Europa diferente, muy distinta de su configuración actual. Este artículo presta atención a diversos episodios y contextos, como la crisis de 2008 y sus efectos sobre la Eurozona. También sobre las transformaciones jurídicas y políticas que acompañan a la oligarquización del proceso, que entiendo están en la base de una involución democrática y social que ha arrebatado Europa a sus ciudadanos y que como en su mito fundacional la conducen hacia un destino que se antoja crepuscular y laberíntico.

El texto se ha elaborado sobre la base de pequeños fragmentos discursivos y gira en torno a cuestiones con las que vengo trabajando desde hace algunos años y que han dado pie a algunas contribuciones académicas y en prensa $^{4}$. En mi opinión, la carencia de una opinión pública europea ha facilitado la deriva oligárquica del proyecto, pero me parece una ingenuidad creer que la inexistencia de redes comunicativas europeas: radios, televisiones, diarios de ámbito continental sea casual. En un tiempo de comuni-

${ }^{3}$ Según Eurostat, un tercio de los jóvenes entre 18 y 24 años del área mediterránea de la UE ni estudian ni trabajan. En España, según la Agencia Tributaria, la mayor parte del trabajo que se les ofrece, $74 \%$, es precario, es decir temporal y con salarios por debajo de los 645 euros mensuales. Vid: http://www.elmundo.es/economia/2014/11/21/546e5c3dca4741a15b8 b457d.html.

${ }^{4}$ En particular en el diario Deia donde desde hace 4 años vengo publicando mensualmente artículos sobre Europa y otras cuestiones políticas. 
cación digital considero que ese vacío resulta funcional para los intereses corporativos que se han adueñado de las instituciones europeas y que no desean una opinión pública europea que pueda sustentar una democracia en la UE. Desde el inicio, el debate europeo ha sido siempre algo lejano y limitado a pequeños núcleos académicos; dominado por la tecnicidad y la fe europeísta que ha impuesto una visión institucional y propagandística. El consenso oficial y la falta de empatía con el disenso sobre el modelo de integración ha marginado y ninguneando a las posturas y autores más críti$\cos ^{5}$. Ha debilitado la tarea intelectual hasta conducir a una suerte de pensamiento único y ha desembocado en el alejamiento entre las instituciones europeas y las opiniones públicas nacionales. El rechazo del Eurogrupo a admitir una oposición a la orientación de su política-económica, como se puso en evidencia con ocasión de la crisis griega, es un ejemplo de la falta de pluralismo que caracteriza a las élites tecnocráticas y a las instituciones no mayoritarias que lo conducen.

No se si aún estamos a tiempo de volver a confiar en Europa. Para poder intentarlo es preciso, a mi juicio, mirar a la integración realmente existente. Tal vez entonces se pueda comprender mejor la naturaleza del OPNI delorsiano $^{6}$. Estas líneas quieren también contribuir a hacer visible la impostura neoliberal que se cubre de europeísmo y que a mi juicio se asemeja a una suerte de delusión archimboldiana. La constante invocación al mercado es un recurso del credo neoliberal para disimular que la acumulación y la desigualdad son sus valores fundamentales. Una ideología que pretende desestatalizar el mercado y ponerlo a su servicio, salvo para socializar pérdidas, y que en su falsificación europeísta rechaza los valores políticos que han estado asociados al moderno Estado europeo ${ }^{7}$. Sus efectos, en mi opinión, no pueden conducir a la integración de Europa sino más bien a su fracaso.

${ }^{5}$ Un ejemplo del ninguneo académico es el poco eco de un trabajo extraordinario: ANDERSON, P., El Nuevo Viejo Mundo, Madrid: Akal. 2012. Una valoración de esta obra en: SCHMITTER, P., «Como clasificar una anomalía», en SCHMITTER, P., New Left Review, n. ${ }^{\circ}$ 73, 2012, pp.18-25. Una contestación del autor en: ANDERSON, P., «A Posteriori», n. ${ }^{\circ}$ 73, 2012, pp. 43-54. Su respuesta es un desapasionado análisis crítico del optimismo oficioso de la Europa havermasiana.

${ }^{6}$ Como recuerda Anderson citando a Tocqueville: «La palabra que define a esta nueva forma de gobierno todavía no existe». ANDERSON, P., op.cit., p.146.

${ }^{7}$ En su citada obra, ANDERSON, P., El Nuevo Viejo Mundo, op.cit., pp. 93-146, realiza una revisión crítica de las interpretaciones neoliberales de algunos teóricos de la integración. Tanto de economistas como Gillingham o Eichengreen como de politólogos como Moravsick que justifican el dominio tecnocrático, o del papel dominante de los organismos regulatorios que defiende Majone. También revisa las aportaciones de Parsons o de Zielonka, o de teóricos que como Siedentop, Weiler o Schmitter proponen una democratización limitada de la UE. Un panorama de las múltiples interpretaciones al OPNI delorsiano en: MARISCAL BERASTEGUI, N., Teorías políticas de la integración europea, Madrid: Tecnos, 2003. 


\section{EI horizonte neoliberal de la UE y su crisis de legitimidad}

El proceso de integración europeo ha experimentado un viraje neoliberal y la UE se ha convertido en un instrumento decisivo para acabar con el paradigma del estado social. De manera gradual, a fuego lento y de forma inadvertida se ha ido desarrollando una gran transformación. Aunque la crisis de 2008 ha sido el gran detonante y la globalización el contexto para acelerar la marcha hacia el horizonte neoliberal, el cambio de orientación se ha ido fraguando desde los años ochenta. Tras la II Guerra Mundial en los Estados de Europa occidental, y en particular en los seis que fundaron las tres Comunidades Europeas, se había articulado una alianza política entre la clase trabajadora y la clase media que resultó durante décadas electoralmente mayoritaria. El resultado fue lo que se denominaron Estados de bienestar. Una convergencia que implicó a partidos políticos de orientación socialista, a la democracia-cristiana ${ }^{8}$, e incluso a fuerzas liberales. También a sindicatos y organizaciones patronales. Su consecuencia fueron los denominados treinta gloriosos: tres décadas orientadas al pleno empleo y crecimiento $^{9}$. Sin embargo, a comienzos de los años ochenta eclosionará una reacción a ese modelo de democracia consociacional. Inspirada en el credo neoliberal friedmaniano, el thatcherismo en Reino Unido y la reaganomics en EE.UU. promoverán un desmontaje agresivo del keynesianismo. En los noventa, con la caída del bloque soviético el acoso neoliberal se acelerará y así, en EEUU durante el segundo mandato de Clinton se llevará adelante una desregulación bancaria que pondrá fin a la legislación vigente desde los años treinta y que propiciará la financiarización de la economía. En Europa, y en términos políticos, el blairismo impulsará una asimilación enmascarada de la socialdemocracia al neoliberalismo que se denominará tercera vía. Por su parte, la «popularización» de las democracias cristianas las diluirá en una corriente de conservadurismo que pondrá fin a su original impronta social.

La antigua confrontación entre izquierda y derecha concluye cuando la socialdemocracia y el pensamiento social cristiano se convierten en alternativa edulcorada al gobierno de los partidos conservadores y liberales, renunciando al paradigma de la superioridad de la política sobre el mercado. Se abre entonces un nuevo tiempo en torno al centro político en el que todavía orbitamos. Una entelequia para disimular el desplazamiento del con-

${ }^{8}$ El Papa Leon XIII en su celebre encíclica Rerum Novarum de 1891 había advertido contra un capitalismo de mercado que favorece «la acumulación de la riqueza en pocas manos y la miseria de la mayoría».

9 Un relato clásico de ese proceso en: MILWARD, A., The European Rescue of the $\mathrm{Na}$ tion-State, London: Routledge, 1992. 
junto de las fuerzas políticas hacia un credo de radicalidad económica cuyo epicentro se ha desplazado muy a la derecha. Un ejercicio geolingüístico que ha transformado a unos en populares y a otros en progresistas en un común empeño por disimular la convergencia a favor del fundamentalismo de mercado como nuevo y definitivo paradigma de legitimación política. Vivimos como si a la pretérita vocación de algunos por la dictadura del proletariado le hubiera sustituido la voluntad de otros por imponer una dictablanda de mercado. Un contexto neoliberal donde en la UE se ha consolidado una Gran Coalición que impulsa un proyecto de transformación radical que ha alterado los contratos sociales sobre los que se habían reconstruidos los Estados-nación desde la postguerra.

El Estado social de mercado que había sido la gran aportación europea al desarrollo democrático se ha convertido para el nuevo paradigma en una rémora al crecimiento y al progreso. La propaganda neoliberal difunde incansablemente un mensaje opuesto a la universalización de los derechos sociales que en lugar de ciudadanos prefiere consumidores o litigantes. Un asalto al Palacio de Invierno de los poderes públicos que se mantiene sin tregua: con el asedio a la sanidad universal, a la educación pública, o a los seguros de desempleo. Una ofensiva ante la que tanto la socialdemocracia como el cristianismo social han ido reculando, asumiendo los postulados de un capitalismo desbocado y limitándose a proponer medidas compensatorias. En ese marco los tratados europeos, en especial a partir de Maastricht se van a convertir en arietes que favorecen el cambio de paradigma, impulsando el aumento de poderes de las instituciones europeas según una lógica de integración que elude la dimensión social del mercado. Un ejemplo elocuente de ese objetivo asocial será mantener el presupuesto comunitario en un $1 \%$ del PIB europeo, como vía segura para poder limitar las políticas de redistribución social y territorial. O negarse a reconocer a la UE una capacidad fiscal directa que no dependa de las contribuciones de los Estados Miembros.

$\mathrm{Al}$ capitalismo industrial que estaba en el origen del proceso de integración le sucede otro modelo que arrincona a la industria como eje. La liberalización de los flujos de capital, la expansión del crédito, el comercio digital y la capitalización de los fondos de pensiones y seguros sociales se convierten en los vectores dominantes de un capitalismo financiarizado ${ }^{10}$. Para las tesis del fundamentalismo neoliberal, el mercado es un marco eficiente y estable que no necesita de la intervención del Estado. En realidad

${ }^{10}$ Una extensa explicación sobre esa transformación en: GARCIA HERRERA, M.A., «Estado económico y capitalismo financiarizado: propuestas para un constitucionalismo crítico», en ASENSI SABATER, J. Y BALAGUER CALLEJON, F. (coor.), Constitucionalismo Crítico, Valencia: Tirant lo Blanch, 2015, pp. 137-242. 
esa base ideológica sirve para promover una catarata de beneficios fiscales, subvenciones y desregulaciones que inducirán a la fusión de grandes empresas de carácter oligopólico hasta convertir al sector de los servicios financieros en hegemónico, concentrando allí la mayoría de los beneficios del crecimiento económico. Un cambio de modelo que no ha sido la consecuencia de una intervención extraterrestre, como alguno podría deducir de la invocación al OPNI delorsiano, sino que ha sido inducido políticamente por poderes de este Planeta que han promovido cadenas productivas globales dando una nueva dimensión a las viejas economías de escala nacionales ${ }^{11}$. Si en 1990 las multinacionales eran responsables del $20 \%$ del PIB mundial hoy lo son de casi la mitad y ya en 2002 China contaba con más trabajadores industriales que todos los países del G-7. Las desigualdades entre naciones han dado paso al aumento de las desigualdades locales y a que globalmente se abra un abismo entre quienes más tienen y todos los demás. Sucesivos estudios han advertido sobre la acumulación de la riqueza global en unos miles de personas y que la democracia social está siendo sustituida por una democracia formal o decorativa al servicio de los intereses de los más ricos ${ }^{12}$.

En tanto que abanderada y avanzadilla de la liberalización mercataria, la UE se ha ido convirtiendo en un motivo de inquietud para su población. Su apoyo a las recetas neoliberales ha conducido a una crisis de confianza cada vez más generalizada, donde más gente interpreta que más Europa es equivalente a menos democracia y a más injusticia social. La retórica europea asociada a los derechos humanos ha ido también perdiendo credibilidad. Su pasividad en la guerra de Bosnia o su connivencia con la denominada lucha contra el terror promovida por la Administración Bush ha satelizado a la UE que se ha prestado a colaborar en escuchas ilegales, secuestros y detenciones. Las instituciones europeas se han asociado a un clima de inestabilidad permanente de consecuencias imprevisibles que la han arrastrado a aventuras como las de Afganistán e Irak o a la desestabilización de Libia, Siria o

11 De igual manera que la formación de la Europa moderna entre 950 y 1350 fue también consecuencia de procesos de conquista, colonización y cambio cultural. Vid., BARTLETT, R., La Formación de Europa, Valencia: PUV, 2003.

12 Oxfam international advierte en su informe anual de 2014, n. ${ }^{\circ} 178$, que en 2016 el $1 \%$ de la población mundial contará con más recursos que la mitad de la población mundial. Vid., http://www.oxfamintermon.org/sites/default/files/documentos/files/bp-working-for-few-political-capture-economic-inequality-200114-es.pdf. Según otros datos, 1226 personas cuentan con más recursos que el PIB de Alemania, de ellas 425 son estadounidenses. Al mismo tiempo, el quintil superior de la población de Bolivia, Indonesia o Nicaragua cuenta con un mejor índice de desarrollo humano (ingresos, educación, esperanza de vida) que el quintil inferior de EE.UU. donde 9/10 partes de la población han perdido terreno desde 1980. Vid: THERBORN, G., «Las clases en el siglo XXI», New Left Review, n. . 78, 2013, pp.11-38. 
Ucrania $^{13}$. La falta de definición de los planes de construcción europea ha facilitado que la UE se fuera pareciendo a un laberíntico edificio en el que una lógica ultraliberal de mercado se ha convertido en la llave maestra con la que poder abrir las puertas de los Estados sociales y remodelarlos. En lugar de la euforia asociada a los planes de la Agenda Europea para 2020, que preveían que Europa iba a liderar el planeta, en apenas una década hemos pasado a un presente de aguda depresión ${ }^{14}$. No sólo el crecimiento de la UE ha sido siempre inferior al de EEUU, sino que el de la eurozona ha sido aún menor que el de antes de existir el euro. El crecimiento vinculado al Mercado Único pronosticado por el Informe Cecchini que lo calculaba entre un 4,3 y un $6,4 \%$ apenas ha superado el $1 \%$ a lo largo de los años ${ }^{15}$. En realidad, el modelo de economía neoliberal que se impulsó con la globalización supuso la desaceleración del crecimiento y vino acompañada de una sustancial perdida adquisitiva de los salarios. Como compensación se recurrió a dopar la demanda mediante crédito masivo y una especulación bursátil e hipotecaria que han provocado sucesivas burbujas. A los ciclos expansivos les sucedieron dramáticas contracciones que culminarían en la crisis de 2008.

El discurso del narcisismo europeo ha pretendido ver en la UE un agente de democracia para el mundo, obviando la concentración de más y nuevos poderes en el Consejo Europeo, con sus deliberaciones convenientemente insonorizadas más allá del control de la ciudadanía y de sus parlamentos. Pero el nuevo modelo de capitalismo oligárquico ha llegado acompañado de un sistema post-democrático donde la orientación del gobierno europeo no depende, salvo remotamente, del electorado. En la UE las elecciones europeas no se celebran para poder elegir un gobierno europeo ni sirven para cambiar sus políticas ${ }^{16}$. Al mismo tiempo, los sistemas

${ }^{13}$ La administración Bush liderada por Cheney y Rumsfeld liquidó el orden internacional aduciendo un derecho de intervencionismo «moral» para justificar invasiones y desestabilizaciones en diferentes países.

${ }^{14}$ Para un relato de las últimas décadas: FILIBI, I., «La Unión Europea veinte años después de Maastricht: hitos y retos», Cuadernos Europeos de Deusto, n. ${ }^{\circ}$ 50, 2014, pp. 19-50.

15 ANDERSON, P., op.cit., p. 64.

${ }^{16}$ La literatura especializada en la UE suele contentarse con plantear esquemas teóricos o aplaudir los tímidos pasos hacia la parlamentarización. Un botón de muestra en: PRIEGO, A. y ABAD, G., «La parlamentarización del sistema político de la Unión Europea: Sus consecuencias para la legitimidad», Cuadernos Europeos de Deusto, n. ${ }^{\circ}$ 52, pp.17-37. También: MULLER GOMEZ, J. and WESSELS, W., «The EP 2014 elections and their consequences. A further step towards EU parlamentarism», Cuadernos Europeos de Deusto, n. ${ }^{\circ}$ 52, 2015, pp. 39-66; ARREGUI, J., «Problemas de legitimidad democrática, representación y rendimiento de cuentas en el proceso político de la Unión Europea», Cuadernos Europeos de Deusto, n. ${ }^{\circ}$ 46, 2012, pp. 85-112; PETITHOMME, M., «La despolitización de la política europea y el dilema del déficit democrático», Cuadernos Europeos de Deusto, n. ${ }^{\circ} 39,2008$, pp. 137-167. 
parlamentarios de los Estados miembros han pasado a ser dependientes de instituciones oligárquicas (no mayoritarias) como el BCE o el Consejo Europeo, donde algunas decenas de personas concentra el poder sobre centenares de millones. Sin embargo, desde la crisis de 2008 el acelerado desplome de la confianza en la Unión Europea, reducida a un 30\%, resulta perturbador. La crisis de 2008 ha provocado una reacción euroescéptica cuyos representantes han sumado entre un 20 y un $25 \%$ de los votos en las últimas elecciones europeas de mayo de 2014. El populismo eurofóbico y los euroescéptico cuentan ahora con entre 150 y 200 escaños. Además, ganaron las elecciones en Estados tan significativos como el Reino Unido, Francia e Italia, y obtuvieron buenos resultados en Holanda, Dinamarca, Austria y varios países del este. La abstención que ha ido en aumento desde 1979 alcanza ya casi un 60\%. A la crisis política del europeísmo se suma otra de resultados económicos. Las políticas europeas en lugar de seguir procurando bienestar, tal como lo hicieron durante medio siglo, han favorecido en la última década el desempleo y la precarización y han impuesto una rigurosa dieta económica a base de ajustes presupuestarios, contención del déficit y reducción de deuda. Hoy 27 millones de ciudadanos, la mitad menores de 24 años, viven en paro. Como si todo el Benelux no tuviera trabajo. La crisis y su respuesta ha desencadenado un distanciamiento inédito entre los ciudadanos y la UE que afecta también a las relaciones entre Estados Miembros.

Las sucesivas transferencias y delegación de materias estatales a las instituciones europeas han acelerado una progresiva oligarquización de la política en Europa. Los Estados miembros han ido concentrando en el Consejo Europeo los poderes de dirección intergubernamental de la Unión Europea debilitando a la Comisión y a otras instituciones. Pero aunque la Unión Monetaria ha pasado a ser una de las tareas principales del Consejo Europeo éste no ha conseguido aportar estabilidad económica ni tampoco institucional. Sin embargo, desde Bruselas las burocracias políticas han conseguido eludir los controles parlamentarios y mediáticos que caracterizan a las democracias nacionales. Un contexto en que no debe obviarse el papel del COREPER (Comité de Representantes Permanentes) que ha sido el auténtico núcleo decisional comunitario. La mayoría de las decisiones que formalmente adopta el Consejo en sus diversas formaciones ministeriales, en la práctica han sido ya resueltas previamente a nivel de COREPER. A este poder burocrático se suma la oligarquización de las grandes orientaciones políticas a través del Consejo Europeo. Una institución compuesta por treinta personas, los jefes de gobierno de los 28 Estados más el presidente de la Comisión y del Consejo Europeo, quienes definen en reuniones que no son públicas las orientaciones generales de la economía y de la política de la Unión. Desde su institucionalización en Maastricht, el Consejo 
Europeo, ha ido desplazando a la Comisión e incluso al Consejo de Ministros como centro de poder de la UE. También el BCE acumula, con la crisis, un enorme poder al margen de control democrático. Los presupuestos de los parlamentos nacionales han pasado a ser supervisados y controlados por la Comisión antes de su tramitación. Una facultad de fiscalización que no existe en los Estados federales, donde Washington no puede controlar el presupuesto de ningún estado de la Unión. Vivimos la paradoja de una política (europea) sin democracia y una democracia (estatal) sin política. La ciudadanía europea no puede elegir o cambiar un gobierno europeo a través de las elecciones al Parlamento Europeo. Sin embargo, las instituciones europeas pueden definir o alterar las políticas estatales. Desde hace años las grandes decisiones políticas y económicas que afectan a la ciudadanía europea se adoptan por instituciones públicas y privadas en Bruselas, Washington o Nueva York, Berlín y Frankfurt, y cada vez más también a orillas del Pacífico.

\section{El contexto de la Globalización}

$\mathrm{Al}$ déficit de legitimidad democrática de la UE se suma otro de eficacia y resultados consecuencia de la impronta neoliberal de la globalización ${ }^{17}$ que está afectando seriamente al proceso de integración europeo. En la mayoría de los estados miembros ha provocado graves problemas sociales y presupuestarios. De los 27 millones de personas desempleadas en la UE, cinco millones y medio son jóvenes menores de 24 años. Cifra que en los últimos cuatro años ha aumentado un 50\%. Inadvertida durante años, a la globalización le acompaña un ajuste global que avanza a toda velocidad. El desarrollo tecnológico que permite producir y transportar mercancías en tiempo récord ha hecho de las grandes corporaciones, que han tejido las redes de esta lógica globalizadora, sus principales beneficiarias. Sacan provecho, muy en particular, de tener a su disposición mano de obra en todo el planeta y que, por ejemplo, la hora de trabajo en China pueda costar 0,5 euros, lo que posibilita a algunas empresas rebajar los costes en la UE o en EE.UU. hasta 16 veces. En otras partes de Asia, como Bangladesh o Vietnam, el salario puede ser aún más reducido: cuatro veces más pequeño que en China. Quienes cosen ropa en condiciones de semiesclavitud por 1 euro al día, en jornadas de diez horas durante seis días a la semana, ganan 0,12 centavos de euro a la hora, es decir, sesenta veces menos que en la UE o

17 Una buena presentación de ideas y autores en: BOCKER, R., «El discurso de la globalización neoliberal», Sistema, n. ${ }^{\circ} 237$, pp. 3-18. 
USA. Otras ventajas, o más bien vulneraciones de carácter medioambiental, así como la falta de libertades, han impulsado el traslado y la concentración masiva de la producción en Asia. Como consecuencia, millones de personas en Europa y en Estados Unidos han perdido su trabajo y la posibilidad de construir una vida con dignidad. Desde una perspectiva global pudiera parecer que el empobrecimiento de algunos en occidente se compensa con la salida de la pobreza de otros en oriente. En realidad, unos y otros forman parte de una inmensa legión de desposeídos. En China, la alteración del orden público equivale a cinco años en un campo de trabajo; en Bangladesh, la sindicación conduce a una lista negra; en Vietnam, el régimen no admite oposición...

Un estudio de la prestigiosa ETH de Zúrich, cuna de más de veinte premios Nobel, ha expuesto, tras analizar treinta millones de empresas, un núcleo de 147 grandes corporaciones que configuran lo que anónimamente denominamos «los mercados» ${ }^{18}$. Un equipo que agrupa nombres casi tan conocidos como algunas alineaciones históricas de fútbol: Barclays, Fidelity Axa, JP Morgan, UBS, Merryll Lynch, Citigroup, Deutsche Bank, Credit Suisse, Natixis, Goldman Sachs, Morgan Stanley... Estas corporaciones son a su vez propietarias de las mayores empresas multinacionales. Otra alineación casi tan conocida: Microsoft, Wells Fargo, Coca-Cola, Philip Morris, Hewlett Packard, Kraft, Monsanto, Starbucks, Procter\&Gamble, Johnson\&Johnson... El estudio destaca también que estas compañías comparten la propiedad de muchas de ellas, que hay un entrecruzamiento accionarial. Sus principales accionistas forman parte de las cerca de 60.000 personas que en el mundo tienen un patrimonio superior a 100 millones de dólares. Además, algunos son también milmillonarios. Un grupo de unas dos mil personas con una fortuna superior a los mil millones de dólares.

Las grandes corporaciones, «los mercados», no sólo acumulan; además, apenas tributan. El dumping fiscal que practican afecta gravemente a las arcas públicas. El volumen de negocio que manejan cada vez es mayor: en un par de décadas han eliminado de la competencia a millones de autónomos. Los paraísos y la elusión fiscales les permiten, como por ejemplo a Amazon, que en Europa tributa en Luxemburgo, pagar sólo el 0,24\%. A través de lo que se denomina «ingeniería de matrices», que consiste en ir derivando los beneficios hasta el territorio fiscal más favorable, las corporaciones eluden barreras tributarias y escapan de hacienda. Las siete grandes tecnológicas (Google, Apple, Facebook, Yahoo, Amazon, eBay y Microsoft) tributan en la UE en torno a un 0,2\%.

18 Un resumen del estudio y un listado de las 50 empresas más relevantes en: https:// www.newscientist.com/article/mg21228354.500-revealed--the-capitalist-network-that-runsthe-world. 
Semejante modelo de globalización ${ }^{19}$ se ha desarrollado con el apoyo de algunos actores institucionales y la colaboración de numerosos políticos. Su gestación ha llevado décadas y ha contado con el apoyo de algunos agentes institucionales ${ }^{20}$. La globalización neoliberal no es el resultado de un desarrollo espontáneo sino de un proceso tutorizado, desde que cerca de la conclusión de la II Guerra Mundial, en Breton Woods, se establecieron las bases del nuevo orden de postguerra. En ese contexto, y para procurar estabilidad a un sistema capitalista en vías de globalización, el proceso de integración europeo recibió un empuje decisivo desde EEUU quién apostó por promover el desarrollo de dos de sus recientes enemigos: Alemania y Japón. América necesitaba una vez terminada la guerra contar con epicentros de mercado hacia donde conducir sus exportaciones. Su gigantesca capacidad productiva estimulada con el conflicto bélico necesitaba contar con millones de consumidores en Asia y en Europa. La Comunidad Económica Europea no fue sólo el resultado de la voluntad de unas élites continentales por establecer un nuevo paradigma para la paz, el desarrollo y el bienestar. El plan Marshall que precedió a la CECA sentó las bases para una cooperación europea en el marco de un Plan Global. Cuando a principios de los años setenta, la administración Nixon terminó con la convertibilidad del dólar y el patrón oro fue abandonado, el doble déficit, presupuestario y comercial, de EE.UU. pasaría a ser financiado con las transferencias financieras que desde Europa y Japón fluirán hacia Wall Street. Ese mecanismo invertido de reequilibrio y compensación, denominado por Varoufakis como Minotauro Global ${ }^{21}$, siguió funcionando como elemento articulador de la globalización, ya extendida a otros lugares como el sudeste asiático, China o el antiguo imperio soviético, hasta el crack de 2008. A partir de entonces el espacio económico global se ha vuelto imprevisible y la crisis de Wall Street trasladada al euro es una manifestación de los desequilibrios políticos a los que conducen las asimetrías de las zona económicas - mundial y europea - que no cuentan con un mecanismo capaz de equilibrar las áreas excedentarias y deficitarias del mercado.

19 FRASER, N., «¿Triple Movimiento?. Entender la política de la crisis a la luz de Polanyi», New Left Review, n. ${ }^{\circ}$ 81, 2013, pp.125-139.

${ }^{20}$ LASA LOPEZ, A., «La contribución de la Unión Europea a la gobernanza económica mundial ante la crisis del paradigma globalizador», Cuadernos Europeos de Deusto, n. ${ }^{\circ} 45$, 2011, pp. 67-96. Este texto da cuenta del desplazamiento que desde Maastricht la UE ha venido impulsando para reemplazar al Estado social por un modelo de Estado constitucional de mercado. En particular en páginas 241 y siguientes sobre algunas decisiones de los Consejos Europeos para orientar la política económica hacia un paradigma neoliberal.

21 VAROUFAKIS, Y., El Minotauro global, Madrid: Capitán Swing. 2013. Se trata de una convincente explicación sobre el funcionamiento de la economía mundial desde la postguerra hasta el crack de 2008. 
En su origen, el FMI fue encargado con la tarea de procurar recursos financieros en períodos de crisis que pudieran afectar a la estabilidad de la economía global. Pero bajo el control de EE.UU., principal proveedor de crédito, se convirtió en un instrumento para imponer una doctrina neoliberal al servicio de los intereses de Wall Street. Dado que en el reparto de responsabilidades internas del gobierno americano, las decisiones sobre el FMI corresponden a la Secretaría del Tesoro, cuyos máximos responsables han sido, casi sin excepción, representantes de los bancos de inversión, las sucesivas crisis en Asia, Latinoamérica o la incorporación de Rusia al sistema capitalista dieron un enorme poder al FMI, es decir, a Wall Street. La ortodoxia antiinflacionista y la prioridad en devolver las deudas a los bancos se convirtieron en el santo y seña de una política económica global. que invariablemente exigió, a cambio de sus ayudas, un paquete de medidas de ajuste que impusieron un enorme coste en términos de empleo y crecimiento. Con un doble déficit comercial y en especial presupuestario estratosférico, varias veces el tamaño de su PIB, los acreedores de su gigantesca deuda, pública y privada, en particular China, siguen financiando la economía americana. El «privilegio exorbitante» que representa el dólar como moneda internacional le ha permitido a EE.UU. vivir al margen de esas reglas. Hoy como ayer, las letras del Tesoro siguen siendo una inversión que se juzga rentable.

A comienzos del nuevo milenio, Stiglitz, acometió una crítica devastadora del papel del FMI en la globalización. Quien fuera miembro del Consejo Económico de la Casa Blanca y jefe de economistas del Banco Mundial se convirtió en una de las voces más críticas del funcionamiento de la globalización ${ }^{22}$. A su extenso análisis le seguiría una dilatada lista de recomendaciones para «hacer que funcione» ${ }^{23}$. Desgraciadamente, casi nada de lo propuesto ha sido incorporado al hacer del FMI, el BM o la $\mathrm{OMC}^{24}$. De hecho, la globalización ha difundido un modelo de oligarquización de la economía y de la política en el que las grandes corporaciones manejan también las instituciones internacionales como el FMI o el Banco Mun-

${ }^{22}$ En su trabajo: STIGLITZ, J., El Malestar en la globalización, Madrid: Taurus, 2002, el que luego sería Premio Nobel de Economía y desde hace años profesor de la universidad de Columbia, demuestra que las sucesivas intervenciones del FMI han atendido a los intereses de los más poderosos y sus políticas contractivas han provocado millones de damnificados, arrastrando casi sin excepción a los Estados intervenidos a prolongadas recesiones.

${ }^{23}$ STIGLITZ, J., Cómo hacer que funcione la globalización, Madrid: Taurus, 2006.

${ }^{24}$ Por el contrario, el baile de puestos ejecutivos entre instituciones públicas como el FMI y la banca de inversión, sea CityGroup o Goldman Sachs, es una constante. Figuras como Stan Fischer o Robert Rubin, o Jack Paulson en el Tesoro, Geithner o Summers en la Fed son ilustrativos del significado de las puertas giratorias. 
dial, o la OMC. La globalización neoliberal funciona en la medida en que se dan ciertas características productivas que implican una diferencia sustancial entre lo que podemos denominar el Norte o territorio occidental y el Sur: the West and the Rest. Dada la libre circulación de capitales, su internacionalización y concentración, y la también fluida circulación de bienes y su comercialización por todo el planeta, las enormes desigualdades salariales entre la mano de obra, según los países, y cada vez más al interior de las economías nacionales, repercuten de manera decisiva en los precios y en los beneficios, y han sido claves para el desplazamiento industrial hacia Asia. En particular han convertido a China en la fábrica del planeta, y a algunas de sus áreas en una suerte de gigantescos nuevos Manchester, Pittsburgh o Bilbao del siglo XxI. Ciertas condiciones sociales y políticas han estimulado ese masivo desplazamiento productivo. Por un lado, la agricultura ha dejado de ser una fuente de recursos para millones de campesinos, que durante las últimas décadas, principalmente en Asia, se han visto forzados a emigrar hacia zonas urbanas donde para poder sobrevivir o ayudar a sus familias rurales están dispuestos a trabajar en condiciones de sobre explotación laboral con horarios diarios de alrededor de 12 horas y más de 60 horas semanales. Semejantes condiciones laborales se mantienen con el apoyo de gobiernos corruptos ligados a los intereses corporativos que restringen o prohíben la actividad sindical o política. La producción se realiza al margen de los criterios medioambientales occidentales que provocan serios daños a la salud, pero la contaminación de las aguas o el aire, el impacto atmosférico, son costos que no se reflejan en el precio. Daños colaterales que forman parte de lo que algunos autores denominan «valor oscuro». Para poder entender la diferencia entre precio y valor o las externalidades que forman parte del valor oscuro, que no se refleja en el precio, puede resultar interesante tomar como ejemplo de análisis uno de los productos más populares de la globalización: el iPad de Apple, la compañía con mayor valor bursátil del mundo: más de 700.000 millones de dólares ${ }^{25}$.

El iPad como otros productos como los iPhones o los ordenadores son el resultado de gigantescas «cadenas de valores». En un importante trabajo de 2015 de Lauesen y Zak ${ }^{26}$ se concreta una larga investigación sobre las cadenas de producción de $\mathrm{Apple}^{27}$, una compañía que no fabrica,

25 Según la agencia de calificación Standar \& Poor, a finales de 2014 tras Apple las siguientes serían Exxon Mobile con 385.000 millones; Berkshire Hathaway 370.000 millones y Microsoft 349.000 millones.

${ }^{26}$ Los datos están tomados de LAUESEN, T. y COPE, Z., «Imperialism and the Transformation of Values into Prices», Monthly Review, 67, n. . 3, 2015, pp. 54-67.

27 KRAEMER, K., LINDEN, G. y DEDRICK, J., «Capturing Value in the Global Networks: Apple's iPad and Phone», University of California, July 2011, htpp//pcic.merage.uci.edu. 
sino que se dedica a desarrollar, diseñar, patentar y vender una marca. El ensamblaje de los iPads, como el de otros productos, se hace en China a través de empresas subcontratadas. No hace falta advertir que se trata de un modelo que vale para muchas otras marcas internacionales. En su caso, Apple ha integrado cerca de mil proveedores, (748) de materiales y componentes, de los que el $82 \%$ están en Asia, y casi la mitad, (351), en China. Entre la mitad de 2010 y la mitad de 2011 Apple vendió 100 millones de iPads, y su precio de venta fue de 499 \$. Un detallado estudio $^{28}$ sobre el mayor negocio global hasta la fecha, cifra el precio de fabricación en 275 \$. Pero no sólo se trata de un enorme porcentaje de beneficios teniendo en cuenta los costes y el volumen de ventas. Además, de los costos de fabricación, sólo 33 \$ fueron para pagar salarios en el Sur. Por el contrario, $150 \$$ se dedicaron a remunerar la financiación, el diseño, la publicidad, los salarios administrativos y la investigación localizada en el Norte. La enorme desigualdad en la distribución del valor en salarios y beneficios se puede representar mediante una curva de sonrisa conforme a la cual la retribución mayor corresponde a los extremos localizados en el Norte: los dedicados a la preproducción y venta, mientras el punto de inflexión más bajo de retribución se dedica a los costes de la producción concentrada en el Sur. Así, si el iPad hubiera sido configurado en EE.UU. el coste salarial hubiera sido de $442 \$$ y el de manufacturación de los materiales 210 \$ (en lugar de 45 \$ y 35 \$ respectivamente). Pero el menor pago a los trabajadores del Sur no debe atribuirse a su menor productividad, que es mucho mayor, sino a los beneficios que el producto genera al venderse en el Norte, calculo sobre el que se establece esa disparidad. En consecuencia, los consumidores occidentales se benefician de los bajos precios de los productos elaborados en territorios donde los trabajadores son explotados laboralmente y retribuidos muy por debajo del valor de su trabajo. Así, los beneficios que procura a las grandes corporaciones se comparten entre una masa mucho más amplia que el denominado $1 \%$ que concentra su propiedad. La población, básicamente del Norte, obtiene a bajo precio productos de alto coste elaborados en el Sur que además no incorporan a su precio de venta, por ejemplo, los $105 \mathrm{~kg}$ de gases de efecto invernadero que genera la producción de cada iPad generada en aquellos territorios ${ }^{29}$. Así, a los abusos laborales y medioambientales ligados a la globalización se suma a través de las

${ }^{28}$ CLELLAND, D., «The Core of the Apple: Dark Value and Degrees of Monopoly in the Commodity Chains», Journal of World Systems Research, 20, n. ${ }^{\circ}$ 1, 2014, pp. 82-111.

${ }_{29}$ Como tampoco se suelen contabilizar los casi 300 litros de agua o 30 de dióxido de carbono que conlleva su producción. Datos citados por LAUESEN, T. \& COPE, Z., op. cit., p. 65 . 
diferencias entre valor y precio otra dimensión de explotación Norte-Sur que habitualmente no suele dejar rastro en los análisis de la economía global $^{30}$.

\section{Desconstitucionalización, debilitamiento democrático y gobierno corporativo}

El proceso de oligarquización también proyecta una sombra institucional y política sobre el Estado de Derecho y el orden jurídico comunitario. Como reconocía Van Rompuy tras abandonar después de 5 años su cargo de Presidente del Consejo Europeo (2009-14), el gobierno de la Unión Europea funciona a golpe de crisis. Una afirmación ininterrumpidamente corroborada con la crisis del euro. Podría decirse ${ }^{31}$, que la gobernanza europea ha derivado hacia un modelo de estado de excepción permanente, en donde las decisiones se adoptan atendiendo a circunstancias de necesidad y urgencia. Un paradigma en donde la razón económica ha desplazado a la política $\mathrm{y}$ al derecho, y donde el Estado de mercado ha reemplazado al Estado social. Una suerte de constitucionalismo ejecutivo que ha ido convirtiendo el contexto jurídico de la UE en un marco confuso e impreciso donde el Consejo Europeo mediante recomendaciones ha ido imponiendo una suerte de «soft law» que en los Estados Miembros se convierten en leyes, en ocasiones incluso, de rango constitucional. Un contexto jurídico donde además, los Estados Miembros han ido suscribiendo tratados internacionales que puentean a los tratados europeos, y donde una miríada de comités ad hoc y especiales se han convertido en excepcionales pero auténticos centros de poder. Los ejemplos son tan numerosos que podría hablarse de una metamorfosis o mutación constitucional. Un fenómeno aplicable tanto a los ordenes internos de los Estados Miembros como al propiamente europeo. Un proceso del que ya habían advertido algunos autores antes del comienzo del nuevo milenio ${ }^{32}$.

${ }^{30}$ Una batería de datos en: FOSTER, J.B., «The new imperialism of globalized monopoly-finance capital», Monthly Review, n. ${ }^{\circ}$ 67, 2015, pp. 1-22.

${ }^{31}$ CHOFRE, J., «La Unión Europea ante la crisis económica: el «estado de excepción» como nuevo paradigma», en GARCIA HERRERA, M.A., ASENSI, J. Y BALAGUER, F. (coor.), Constitucionalismo crítico, Valencia: Tirant lo Blanch, pp. 593-625.

32 ZOLO, D., Cosmopolis: An approach to World government, Cambridge: Polity Press, 1997; BECK, U., What is Globalization, Cambridge: Polity Press, 1999; HELD, D., Global Transformations: Politics, Economics and Culture, Stanford: University Press, 1999. 


\section{Decisionismo ejecutivo}

En 2008 la crisis va a provocar en la UE una acumulación y centralización de poderes desconocida hasta la fecha. Competencias que hasta entonces estaban en manos de los Estados Miembros van a pasar a la competencia europea. Tras meses de desconcierto, en 2010 se configura el denominado Semestre Europeo que va a conferir a las instituciones comunitarias la supervisión y control sobre los presupuestos nacionales. En 2011 llegará el denominado «Six Pack», un conjunto de 5 reglamentos y una directiva comunitaria para prevenir y sancionar los desequilibrios presupuestarios. Al año siguiente, 2012, es el turno del Tratado de Estabilidad, Coordinación y Gobernanza de la UEM (TECG) y de los programas de rescate de deuda, como el MEEF (Mecanismo Europeo de Estabilidad Financiera) puesto en marcha sobre la base del artículo 122.2 del TFUE que preveía «asistencia financiera en caso de catástrofes naturales o acontecimientos excepcionales». A través de una sucesión de nuevos instrumentos legales al margen de los tratados o con una base en los mismos, jurídicamente muy endeble, se abre la puerta a la intervención de nuevos organismos: Troika, FMI, MEDE. Así, en 2013, un Reglamento conjunto del Consejo y del Parlamento $^{33}$ diseña una estructura de tutela sobre los Estados de la zona euro a cargo del BCE, una Autoridad Europea de Supervisión (AES) y una Junta Europea de Riesgo Sistémico (JERS), previstas en el art.2.2. del citado reglamento. La innovación jurídica dio otro paso adelante con la puesta en marcha del Fondo Europeo de Estabilidad Financiera (FEEF) que se constituiría como una sociedad de derecho privado de la que forman parte los Estados de la eurozona, precisamente para poder sortear los obstáculos de los Tratados. También el Mecanismo Europeo de Estabilidad (MEDE) se configura como una entidad financiera intergubernamental de carácter privado. En concreto, el tratado por el que se constituye el MEDE se firma como acuerdo internacional al margen de los tratados europeos, pero que, para su funcionamiento, se apoya en la estructura institucional comunitaria. Un mecanismo que a cambio de proporcionar financiación a los estados en dificultades cuenta con capacidad ejecutiva para imponer o exigir a los Estados la adopción de medidas de política económica que estaban fuera del alcance de las instituciones europeas: pensiones, impuestos o salarios. Incluso se blinda en su art.35.1. la inviolabilidad de sus archivos y de sus documentos oficiales o la inmunidad de sus integrantes frente a posibles investigaciones sobre su funcionamiento...

33 Reglamento 472/2013. 
La nueva realidad jurídica es que ámbitos de especial transcendencia social y económica de los Estados Miembros han pasado a depender de organismos cuya existencia no se contempla en sus constituciones: BCE, FMI, FEDE, MEDE... Como tampoco los tratados europeos recogen la existencias de un organismo tan importante como el Eurogrupo, salvo una exigua referencia recogida en el Protocolo 14 del Tratado de Lisboa. Una transformación que ya estaba en marcha pero que se ha acelerado con la crisis $^{34}$. Y tampoco la modificación del artículo 136 del TFUE para añadir un nuevo tercer párrafo, conforme a una decisión del Consejo Europeo, parece tener una firme base jurídica ${ }^{35}$. A pesar de su validación por el Tribunal de Luxemburgo en su sentencia Pringle se trata de una decisión que más bien parece otro ejemplo de ingeniería jurídica para sortear los requisitos del artículo 48.6 TUE previsto para aumentar los poderes de la UE vía el procedimiento de revisión simplificada.

La desconstitucionalización del proceso de integración se apoya en la ha tecno-estructura que dirige la UE desde Bruselas y Frankfurt vía Berlín y puede interpretarse como el resultado de una revolución invertida. Como una emancipación de las élites, que pretenden dejar de depender de la voluntad democrática de la ciudadanía. Un nuevo estamento «in the making» de vocación global, móvil y evanescente que impulsa un proyecto neoliberal. La despolitización como contexto social y la inexistencia de un demos europeo son ventajas que favorecen la legitimación oligárquica. Para esta tesis la falta de un sujeto constituyente no es un problema. Por el contrario, se convierte en uno de los argumentos que favorecen a quienes quieren retrasar o impedir un desarrollo democrático. El neoliberalismo ejecutivo que gobierna a golpe de crisis tiene así en las teorías del decisionismo schmittiano un antecedente. Un escenario donde los nuevos organismos de decisión europeos son elevados a la categoría de agentes que adoptan «actos apócrifos de soberanía» al margen del ordenamiento jurídico existente o de sus actores institucionales.

Tal y como detalla el profesor Christian Joerges en un iluminador trabajo sobre la Constitución Económica Europea, la UE vive en un marco político de emergencia dominado por el federalismo ejecutivo ${ }^{36}$. En su

${ }^{34}$ Una descripción de ese nuevo paradigma de gobernanza en: DE MIGUEL, J. y RAMOS TRUCHERO, G., «La crisis y el gobierno económico de la Unión Europea», Sistema, n. 221,2011 , pp. 3-26.

35 Ni en el propio artículo 136 o en el 121 o 126 del TFUE.

36 JOERGES, C., «Pereat iustitia, fiat mundus: What is left of the European Economic Constitution after the OMT-litigation?», Zentra Working Papers in Transnational Studies, $\mathrm{n} .{ }^{\circ}$ 60/2015, 2015. 
análisis de las diferentes posiciones del Tribunal Constitucional Federal Alemán y del Tribunal de Justicia de la UE en relación a sus respectivas competencias, el profesor Joerges advierte en sus conclusiones sobre la incertidumbre democrática que caracteriza a la gobernanza económica de la UE. La jurisprudencia de los casos Gauweiler ${ }^{37}$ y Pringle ${ }^{38}$ emerge en todas sus contradicciones con ocasión del programa asociado a la OMT (Outwright Monetary Transaction) pergeñado para dar respuesta a la crisis de la eurozona. Una crisis que se ha convertido en una suerte de estado de emergencia permanente que sirve de justificación a una gobernanza europea que transmuta los ordenes jurídico-políticos de los Estados Miembros y también el de la propia estructura normativa comunitaria. La pretensión de los tribunales, tanto alemán como del TJUE, de poder ejercer un control efectivo sobre «la lógica del mercado» configurada como nuevo paradigma de legitimación se ha desvanecido con la crisis. La histórica declaración de Draghi advirtiendo que estaba dispuesto a «whatever it takes» ${ }^{39}$ para salvar el euro llevaba implícita el reconocimiento de la irracionalidad que domina el comportamiento de los mercados y la necesidad de una intervención para poder corregirlos. Al mismo tiempo, los efectos taumatúrgicos que provocó esa afirmación sobre la prima de riesgo o sobre la tambaleante moneda europea vienen a reconocer el tremendo poder conferido a una institución que como el BCE es ajena al control democrático de los ciudadanos europeos. La postura del Tribunal de Luxemburgo, sustentada en la posición del Abogado General, Cruz Villalón ${ }^{40}$, admite que el diseño de Maastricht favorable a la distinción entre política monetaria, fiscal y económica, así como la división horizontal y vertical de competencias entre la UE y los Estados Miembros, están en la base de la problemática legal y económica que ha conducido a un desapoderamiento legal y a un debilitamiento democrático. La separación, de un lado, entre la competencia sobre política monetaria como exclusiva de la UE y por otro, que la política económica deba coordinarse entre los EEMM y que la política fiscal se mantenga como propia de los Estados, ha favorecido que aunque los poderes europeos cuentan con una legitimidad democrática, su actuación vaya más allá de sus mandatos y escape al control democrático previsto constitucionalmente ${ }^{41}$. Puede decirse, como apuntan las significa-

37 BVerfG, 2 BvR 2728/13 vom 14.01.2014.

38 Case 370/12, Pringle v.Ireland, Judgment (Grand Chamber) of 27 November 2012, EU: C: 2012:756.

39 Un ejemplo paradigmático de ese empoderamiento es haber sorteado la prohibición del art.123.1 del TFUE validada por los servicios jurídicos de la UE.

\footnotetext{
40 JOERGUES, op.cit, p.8.

41 Ibid., p.8.
} 
tivas críticas de Schlesinger o Böckenförde ${ }^{42}$ que el diseño de la eurozona fue erróneo, que no tuvo en cuenta las diferencias de cultura económica entre los EEMM o los riesgos de una unión monetaria sin unión política. En opinión del profesor Joerges, la alternativa adoptada «one size fits all» se ha demostrado ingenua, en el mejor de los supuestos. En la práctica ha conducido a la sustitución del ordoliberalismo y su constitucional base legal por el paradigma neoliberal caracterizado por un decisionísmo económico alérgico al control democrático. Los poderes presupuestarios son el fundamento de las democracias parlamentarias, así como la base para las políticas sociales de redistribución de la renta y de la riqueza. Su supervisión y control por órganos supranacionales cuya legitimidad democrática cada vez es más lejana plantea un inquietante futuro. En la recta final de su trabajo, Joerges, oscurece las conclusiones de su análisis. El empleo de términos como «Verfassungswirklichkeit», «zero-choice democracy» o la evocación al Estado de emergencia de Carl Schmitt ${ }^{43}$ proyectan un clima de cierta angustia normativa. Un oscuro panorama jurídico-político en donde la democracia constitucional estaría siendo sustituida por reglas tecnocráticas; y donde la condicionalidad en relación a la estabilidad de los precios se habría convertido en un argumento para transformar los principios de igualdad, respeto mutuo y cooperación entre Estados por el dominio y el control de las relaciones entre Estados acreedores y deudores.

La crisis ha sido la oportunidad para que desde la instituciones europeas se haya inducido a alterar los textos constitucionales, a cambiar gobiernos o a seguir determinadas políticas. Así, en 2011, una suerte de annus horribilis para la democracia, varios países del arco mediterráneo se plegaron a cambio de ayudas financieras a las transformaciones demandadas por diferentes autoridades europeas. En España a la reforma del artículo 135 de la $\mathrm{CE}$ le siguió una ley orgánica ${ }^{44}$ para vincular a todas las administraciones públicas: central, autonómica, local o de la Seguridad Social, a la disciplina presupuestaria. Un «ajuste jurídico» en donde el BCE o el presidente del eurogrupo actuaron como auténticos poderes de facto. Aunque carecían de atribuciones legales o legítimas, reconocidas en los ordenes constitucionales o en los tratados europeos, presionaron a los poderes constitucionales de Portugal, España, Italia o Grecia para inducirlos a adoptar importantes decisiones. Por ejemplo, el entonces presidente del eurogrupo, Jean-Claude Juncker, advirtió a Portugal que cual-

42 Un antiguo director del Bundesbank o un ex miembro del BVerfG respectivamente, cuyas opiniones se recogen en ese mismo documento del Profesor Joergues antes citado.

43 JOERGUES, op.cit., p.14.

44 Ley orgánica de 2/2012 de 27 abril. 
quiera que fuese el resultado de las elecciones portuguesas, el gobierno resultante debía llevar adelante una política de recortes: «gobierne quien gobierne» ${ }^{45}$. Unos meses más tarde, el BCE se dirigió por carta al primer ministro español con sugerencias que dieron lugar a un cambio constitucional ${ }^{46}$. Un procedimiento semejante se empleó también con Italia en donde además se había inducido a formar un gobierno «técnico» ${ }^{47}$. Y en Grecia, a finales de ese año, el primer ministro griego, Papandreu fue sustituido por el vicepresidente del BCE y ex gobernador del banco de Grecia, Lukás Papademos.

Como han denunciado diferentes autores ${ }^{48}$ vivimos un tiempo de reconquista oligárquica donde nuevos poderes salvajes y antidemocráticos actúan como soberanos fragilizando la relación entre democracia y capitalismo que había alumbrado al Estado Social. El neoliberalismo es una nueva corriente diferente al liberalismo clásico o al social-liberal que pretende que el Estado se limite a garantizar un marco constitucional favorable a las libertades empresariales, los derechos de propiedad y la libertad de comercio. De ahí que no tenga empacho en justificar los rescates a sus principales valedores y beneficiarios: las grandes corporaciones y grupos financieros. Su poder a través del dinero ha sido capaz de corromper la democracia hasta convertir al mercado en el principal eje regulador de la sociedad. Ese paradigma ha permitido la desposesión de bienes públicos, comunes y colectivos, para entregarlos a la acumulación privada. Episodios ${ }^{49}$ de capitalismo depredador en favor de algunos grupos que se comportan como élites extractivas. Los controles y la participación democrática se han diluido en una sociedad del espectáculo que más que ciudadanos quiere consumidores. La desmovilización y deslegitimación de la ciudadanía a través de la televisión basura se alimenta de un clima de apatía e im-

45 http://economia.elpais.com/economia/2011/03/25/actualidad/1301041973_850215. html. En otras declaraciones recogidas en Le Figaro de 29/01/2015, en lo que se conoce como Teorema de Juncker aseguró que. «No puede haber elección democrática en contra de los Tratados europeos».

46 Reforma del artículo 135 de la Constitución Española en $B O E$ de 27 de septiembre de 2011.

${ }^{47}$ La carta firmada por el presidente saliente y el entrante del BCE, Trichet y Draghi, fue dirigida al nuevo primer ministro, Mario Monti, antiguo comisario europeo y exalto dirigente de Goldman Sachs. http://www.repubblica.it/economia/2011/09/29/news/lettera_bce_italia-22397484/

48 FERRAJOLI, L., Poderes salvajes. La crisis de la democracia constitucional, Madrid: Trotta, 2011; PISARELLO, G., Un largo Termidor. La ofensiva del constitucionalismo antidemocrático, Madrid: Trotta, 2011.

49 La privatización de Britishpost o de Euskaltel son ejemplos paradigmáticos de una venta a fondos de inversión por debajo de su valor bursátil, tras un proceso previo de externalizaciones y otro posterior de reparto de beneficios a favor de la cúpula dirigente. 
potencia. Una suerte de totalitarismo light que en lugar de movilizar a las masas procura su atomización y pasividad y que va dando pie a un Estado dominado por los intereses corporativos y la seguridad en donde la democracia formal va sustituyendo a una democracia sustancial. Un proceso de deconstrucción en el que el dogma de la religión política democrática, la soberanía popular, está siendo desplazado paulatinamente, para que esa transformación resulte más aceptable y asumible.

Para el constitucionalismo social la economía debe estar al servicio de la sociedad y la incorporación de los derechos sociales ha estado ligada al reconocimiento de la pluralidad del orden político. En contraposición, para el proyecto neoliberal no hay alternativa al dominio mercatario. Las garantías sociales y prestacionales han venido cumpliendo funciones correctoras de un sistema donde a una legitimidad de orden formal o procedimental se añadía otra de carácter sustancial. Esa fórmula democrática está en contradicción con el actual modelo europeo donde la integración no incorpora garantías sociales. Frente a las constituciones garantistas de los Estados Miembros la constitución europea es débil y se limita a dar cobertura a una sociedad que vive para el mercado. Un marco en donde el crecimiento económico está dirigido a la acumulación de la rentabilidad del capital y a la estabilidad de los precios.

Con el proceso de integración y la globalización los demos nacionales han perdido efectividad. De un Estado legislativo y judicial se ha avanzado hacia otro de carácter ejecutivo con un constitucionalismo débil ${ }^{50}$. El desmantelamiento efectivo del Estado social transcurre en parte inadvertido, a través de mutaciones constitucionales. De Estados fundados en el trabajo en donde el trabajador se encuentra protegido se ha pasado a otro escenario donde se favorece la precarización y se procuran su vulnerabilidad e inseguridad. El orden económico europeo da cobertura a la ruptura del equilibrio social mediante normas y sentencias ${ }^{51}$ que limitan o no protegen el ejercicio de derechos colectivos a las libertades. Así por ejemplo, la Carta Europea de Derechos y Libertades, a falta de garantías y de leyes de aplicación se ha convertido en un monumento de inefectividad para recuperar el control democrático de los mercados.

${ }^{50}$ MONEREO PEREZ, J. L., «El constitucionalismo social europeo ante los nuevos poderes soberanos», en GARCIA HERRERA, M.A. et altre (ed.), Constitucionalismo crítico, op.cit, pp. 905-945.

51 Entre otras, Viking o Laval. Una interesante selección de sentencias de los últimos 25 años en: ORDOÑEZ SOLIS, D., «La impronta de las sentencias Francovich, Bosman, Kadi Y Factortame en la jurisprudencia de la Unión Europea», Cuadernos Europeos de Deusto n..$^{\circ}$ 50, 2014, pp. 201-220. En particular listado de 32 sentencias fundamentales en pp.218-220. 


\section{Palidez democrática}

A pesar del empeño de algunos periodistas, coachers ideológicos y muchos políticos en hacer creer lo contrario, la democracia no va bien. La imprescindible confianza que debe existir entre representantes y representados brilla por su ausencia. Los políticos se han convertido en uno de los colectivos que más desconfianza despiertan en la ciudadanía, aunque no parece que esa desafección les quite el sueño. En esa extraordinaria novela que es «Il Gattopardo», Tomasi di Lampedusa asegura que para poder mentir a los demás es preciso antes mentirse a sí mismo. La impostura personal en la actividad política se ha extendido a una suerte de impostura institucional. Los valores públicos no se corresponden con los intereses particulares que allí se defienden. En lugares como España y otros Estados del arco mediterráneo asolados por la corrupción la democracia siempre ha estado en vías de desarrollo y en la Unión Europea el déficit democrático es una minusvalía de origen. También en el conjunto de las democracias occidentales se percibe un descrédito y desapego creciente, tanto en lo que se refiere a la participación electoral como en relación al activismo político. En los dos últimos decenios los índices de afiliación a partidos y sindicatos han disminuido espectacularmente y en su conjunto quienes ya no ejercen su derecho al voto se van aproximando a cerca de la mitad de la población. En Europa del este e incluso en las elecciones al Parlamento Europeo la deserción democrática es aún mayor y la abstención supera el 55\%. La consulta referendaria en Escocia o las recientes elecciones catalanas son la excepción a unos porcentajes de abstención desconocidos en las cuatro décadas que siguieron al restablecimiento democrático tras la II Guerra Mundial. Hasta mitad de los años noventa la media de participación electoral en los países de la UE fue entre el 80 y $90 \%$ y la militancia política y sindical agrupaba a decenas de millones. Hoy, en este otoño democrático, la abstención en las recientes elecciones de Grecia y Portugal superó el 45\%, y los antaño partidos de masas, con millones de afiliados en Francia, Italia, Reino Unido o Alemania son hoy corporaciones que sólo agrupan a algunos centenares de miles.

La democracia, en su acepción etimológica, viene a distinguir el gobierno de la mayoría, frente a otros sistemas en los que el poder está en manos de unos pocos, oligarquía, o de una figura única, dictadura. Si la mayoría no participa, difícilmente puede hablarse de un gobierno que represente la voluntad mayoritaria. Ese es el escenario al que nos encaminamos velozmente. Incluso con mayorías parlamentarias absolutas, como es el caso del PP en España, su gobierno apenas representa a 1/3 del electorado. EEUU, considerado un modelo de democracia, es más bien ejemplo de una plutocracia «súper star». Allí, los índices de participación son 
aún más bajos que en Europa, y tanto si se trata de elecciones al Congreso, como de presidenciales o locales no suele superarse el 50\%.de participación. El ciudadano y elector medio americano es más bien la caricatura de Homer Simpson cuando declara que va a votar a los republicanos y a George W. Bush porque es el único que se atreve a decir la verdad: «que todo va estupendamente».

Sin embargo, en las democracias de mercado la realidad contradice la propaganda simpsoniana que insiste en presentar un futuro luminoso. Por el contrario, es procedente preguntarse que está sucediendo para que buena parte del electorado no encuentre sentido en acudir a votar. Son varios a mi juicio los motivos que explican la creciente y masiva abstención que desde hace dos décadas viene caracterizando a las democracias. En particular me referiré a la creciente sensación de que el voto no sirve para poder decidir y de que con independencia del voto las políticas están al servicio de los más ricos. Se ha extendido la percepción de que los parlamentos han perdido el control de la democracia y que en esos foros no se deciden muchas de las cuestiones de relevancia política y económica. La UE es un buen ejemplo del proceso de desparlamentarización, un marco donde el debilitamiento del Estado-nación es también el de un debilitamiento democrático. Un contexto en el que la integración europea se comporta como una avanzadilla de la globalización en tanto que experiencia postdemocrática.

En el marco de la UE muchas de las materias competenciales del Estado se han transferido a las instituciones europeas y ni los gobiernos ni los parlamentos estatales, aún menos los regionales, pueden ya adoptar decisiones que ahora se comparten con otros Estados en foros supranacionales. Como mucho, los Estados pueden adoptar normas de desarrollo sobre políticas que han sido ya decididas en sede comunitaria. Un ejemplo es la orientación de la política económica sustraída en buena medida a la soberanía estatal a través de un tratado internacional como el de «estabilidad, coordinación y gobernanza» que desde 2012 sujeta el presupuesto de los Estados Miembros de la UE a una supervisión tecnocrática. Un escrutinio, conforme a criterios de doctrina neoliberal, que impone sobre los parlamentos atender la deuda pública y el déficit como prioridades macroeconómicas sobre cualquier otro criterio, ya pueda ser el empleo o el crecimiento. Así, aunque por voluntad popular se pueda cambiar de gobierno, no se podrán cambiar las prioridades de la política. De hecho, cambiar de gobierno y seguir con las mismas políticas es algo ya habitual en muchos países. La denominada alternancia entre populares y socialdemócratas, o conservadores y progresistas, hoy se combina también con gobiernos de coalición o de unidad nacional en países donde ambas fuerzas comparten el ejecutivo. En Europa Francia es el ejemplo de alternan- 
cia y Alemania del gobierno de coalición. Mientras Grecia es el ejemplo de que el mismo gobierno se ve forzado a cambiar de política no como consecuencia de otra mayoría sino de que las políticas de gobierno vienen ya impuestas por los mercados oligopólicos que dominan la globalización desde Bruselas (UE) y Frankfurt (BCE), Washington (FMI) o Nueva York (Wall Street).

Si los votos no sirven para decidir las políticas, ¿para qué votar?. Y por otro lado, ¿a quién se vota?. Dada la opacidad de las formaciones políticas se trata de un interrogante relativamente enigmático. En EEUU los grupos de interés y el coste de las campañas electorales han convertido una vieja democracia en una plutocracia floreciente. Hoy es muy difícil encontrar un senador americano que no sea millonario. Aún más difícil un ex senador que no lo sea o que no pretenda serlo. Más de la mitad de los congresistas americanos se convierten en lobistas cuando dejan la política, una reconversión profesional cada vez más popular en Europa a través de las denominadas puertas giratorias. Aunque todavía no hemos llegado a esos extremos, la oligarquización de la política avanza entre nosotros a un ritmo «allegro». No es extraño que buena parte del electorado desconfié de los partidos asimilados a agencias de empleo y frecuentemente también de extorsión. El 3\% es expresión de un capitalismo clientelar y de amiguetes donde las subvenciones y la contratación pública es el horizonte corporativo de la política. No es difícil concluir que mientras no se limite la financiación o los mandatos, y los partidos no se democraticen controlando a sus dirigentes el rostro de la democracia seguirá empalideciendo hasta parecer un fantasma.

\section{Puertas giratorias}

Las instituciones europeas, como los poderes públicos en general, están siendo acosados por los intereses privados de las grandes corporaciones. Diferentes estrategias tratan de poner Europa al servicio de las gran industria o de los grandes negocios. El lobismo y las puertas giratorias son mecanismos para orientar y condicionar las políticas públicas, que quienes disponen de más y mejores recursos utilizan de manera más o menos encubierta. Se trata de un fenómeno cada vez más notorio que en España salpica en particular al PP y PSOE . ${ }^{52}$ La Comisión Europea y la Unión se han dotado de algunos procedimientos que tratan de regular una actividad que em-

52 En España la información sobre decenas de colusiones entre políticos y grandes empresas está disponible incluso en Wikipedia: https://es.wikipedia.org/wiki/Puerta_giratoria_ (pol\%C3\%ADtica)\#En_Espa.C3.B1a. 
plea cada vez más recursos y personas, que como denuncia un reciente informe del CEO (Corporate European Observatory) ${ }^{53}$, incluye a numerosos ex comisarios. Se trata de una cuestión particularmente sensible que merece se le preste atención y que ejemplariza las prioridades profesionales de muchos políticos.

Así, por ejemplo, si nos referimos a los miembros de la última Comisión Barroso (Barroso 2) que cesó en 2014, alrededor de 1/3 de los ex comisarios han sido ya fichados por grandes empresas. Sin embargo, sólo en algunas ocasiones el conflicto de intereses subyacente ha dado lugar a la intervención del denominado comité de ética habilitado para convalidar o limitar el paso a funciones privadas de los antiguos funcionarios públicos antes de que transcurran 18 meses desde su cese como comisarios. Hasta la fecha, sólo de manera marginal se ha bloqueado a antiguos miembros de la Comisión Europea, incluyendo altos funcionarios, el acceso a desarrollar tareas que se sospecha podrían suponer el ejercicio de lobby. Aunque se ha reclamado una normativa más estricta, la Comisión asegura que sus controles funcionan muy bien. Vistos algunos ejemplos que brevemente mencionamos a continuación, cabe preguntarse si hablan en serio. Por citar sólo algunos de los casos más notorios:

- Viviane Reding, la comisaria luxemburguesa durante 15 años y que ocupó las carteras de Educación y Cultura (199-2004), Sociedad de la Información y Media (2004-2010) y Justicia, Derechos Fundamentales y Ciudadanía (2010-2014) ha sido autorizada para, al tiempo que es europarlamentaria, a formar parte del consejo de administración de Nyrstar (una compañía minera), Agfa o la Fundación Bertelsmann, propietaria del homónimo gigante de los medios de comunicación.

- Karel De Gucht, comisario para Desarrollo y Asuntos Humanitarios (2009-2010) y Comercio (2010-2014) no ha tenido problemas para formar parte de la dirección de una empresa de telecomunicaciones (Poximus) y dos grandes grupos financieros (Merit Capital y CVC).

- Neelie Kroes, comisaria para la Competencia (2004-2010) y para la Agenda Digital (2010-2014) se ha incorporado como consultor especial a Bank of Amerika Merrill Lynch, una de las mayores bancas de inversión.

53 The revolving doors spin again, Corporate European Observatory, 2015: http://corporateeurope.org/revolving-doors/2015/10/revolving-doors-spin-again (última consulta $18 / 12 / 2015)$ 
- José Manuel Barroso, dos veces presidente de la Comisión Europea (2004-2014), ha sido autorizado para 22 nuevas funciones. Entre otras: profesor invitado de diferentes universidades, miembro de varias fundaciones, o como miembro del comité organizador de las conferencias Bilderberg o del comité honorario de European Business Summit.

- Otros como Joaquín Almunia han sido autorizados para desarrollar tareas de estudios energéticos promovidos por ENEL; Maria Damanaki, responsable de Asuntos marítimos y pesqueros (2010-14) ha pasado a ser director gerente global de TNC una ONG americana en cuyo consejo de dirección están representadas: Goldman Sachs, Google, Alibaba, o Blackstone Group, inter altre. Su cabeza, Mark Tercek, fue director y socio de Goldman Sachs, donde trabajó durante 24 años. El informe de CEO también denuncia las autorizaciones de empleo a otros antiguos comisarios como: Siim Kallas, Janez Potocnik, Algirdas Semeta o Stefan Füle.

El informe de CEO plantea además mejorar la transparencia y establecer un sistema de incompatibilidades que proteja los intereses comunitarias lo que supondría extender a tres años el periodo de prohibición para cubrir tanto el lobby directo como el indirecto (proporcionar datos a un tercero) y no sólo cubrir las responsabilidades asociadas a la última cartera comunitaria, como sucede actualmente. El ad hoc Comité de Ética establecido, debiera dejar de estar ligado exclusivamente a miembros de las instituciones europeas $^{54}$ y pasar a estar integrado por miembros externos, dotado de los suficientes recursos materiales y humanos como para poder desarrollar sus funciones con eficiencia e independencia para evaluar las tareas remuneradas o no de los ex comisarios, o para ocuparse también de la presidencia del Consejo Europeo.

Como vamos conociendo, aunque sea a cuentagotas, mediante las filtraciones del denominado escándalo Luxleaks, el actual presidente de la Comisión Europea procuró durante años desde su anterior posición como primer ministro de Luxemburgo y ministro de Finanzas, unos beneficios fiscales exorbitantes a la mayoría de las principales multinacionales operantes en la UE. También el actual presidente del eurogrupo, Dijsselbloem, consiguió cuando era ministro de finanzas de Holanda un trato de favor para los mismos intereses a través de los denominados «tax rulings». Recientemente, medios como Der Spiegel y Le Monde han hecho público las actas de dos grupos de trabajo de la Comisión Europea, sobre Código de Conducta Fis-

${ }^{54}$ El comité de ética lo forman: un antiguo director general de la Comisión, un ex europarlamentario y un ex juez del TJUE. 
cal y Cuestiones Impositivas, que han permanecido como confidenciales durante años. Esos documentos revelan el obstruccionismo de ambos mandatarios ante los intentos de algunos Estados comunitarios de corregir esos abusos. La existencia misma del grupo Business Taxation creado en 1998 permaneció oculta a la opinión pública hasta 2014 hasta que con motivo del escándalo del Luxleak el Europarlamento creó una comisión de investigación denominada «Taxe». Las actas de esas reuniones que se prolongaron durante más de una docena de años ponen de manifiesto que los países del Benelux recurrieron a constantes artimañas para prolongar un fraude fiscal masivo. Uno de los recursos consistía en validar una suerte de falsas patentes « license box rules «para simular que las licencias, copyrights y patentes de las grandes corporaciones pertenecían a empresas pantallas que tenían su sede en Holanda o Luxemburgo, donde pagaban tipos fiscales cercanos a cero, de manera que las ganancias, por valor de miles de millones en los diferentes países de la UE, quedaran exentas tributariamente. Dado que en materia fiscal la unanimidad es un requisito, los gobiernos entonces representados por Juncker y Dijsselbloem, luego ambos designados sucesivamente presidentes del Eurogrupo, lograron impedir poner término a estos abusos. Incluso en marzo de 2013, con Djilssebloem como jefe del eurogrupo, Holanda planteó una objeción de naturaleza política, al plan de Alemania y Reino Unido, que había sido avalado por expertos de la OCDE, para acabar con ese entramado ${ }^{55}$. Sin embargo, esas conductas perjudiciales para los intereses de la población europea fueron premiadas con el ascenso de sus máximos responsables a posiciones ejecutivas tanto en el Eurogrupo, Djilssebloem, como en el caso de Juncker, a la presidencia de la Comisión Europea. En ambos casos, con el respaldo de los grupos mayoritarios en la Eurocámara: populares, socialistas y liberal-demócratas: la denominada Grosse Koalition.

Por otro lado, un creciente número de empleados de las grandes corporaciones se convierten en responsables públicos. Un formidable dumping político-institucional que actúa también como una puerta giratoria a la que se accede desde otra dirección. Así, representantes de estas grandes corporaciones financieras han logrado situarse en cargos públicos claves y pasado a dirigir las políticas financieras de estados y organizaciones internacionales. Por mencionar sólo unos pocos ejemplos, Hank Paulson, que durante la última década, tras ser director ejecutivo de Goldman Sachs, se convirtió en secretario del Tesoro americano e impulsó el rescate público de Wall Street por valor de 700.000 millones de dólares. En Europa, otro director ejecu-

55 Diario Publico 12/11/2015: http://www.publico.es/internacional/junckers-y-dijsselbloem-ampararon-personalmente.html. 
tivo de Goldman Sachs, Mario Draghi, se convirtió en presidente del Banco Central Europeo. En España, quien fuera director para la península ibérica de Lehman Brothers, Luis De Guindos, pasó a ser ministro de Economía. Y en Italia, antes de ser primer ministro, Mario Monti trabajó como asesor de... Goldman Sachs. Por esa puerta giratoria circula también un número creciente de políticos que tras dejar sus cargos pasan a trabajar para esas corporaciones. Bien como asesores o mediante invitaciones para impartir conferencias que esas corporaciones pagan en decenas de miles de euros. Así, el candidato de la socialdemocracia alemana en 2013, Peer Steinbrück, que previamente había dirigido la política de privatizaciones como ministro de finanzas, recibió invitaciones de Citigroup, BNP Paribas o JP Morgan para impartir conferencias de entre 15.000 a 25.000 euros por sesión. Poco en relación a Tony Blair, adalid de la tercera vía, quien ha llegado a cobrar más de 100.000 dólares por conferencia, además de fichar como consejero corporativo de JP Morgan. O como el ex ministro de Economía y Trabajo alemán Wolfang Clement, promotor de los minijobs, reubicado como consejero de Adecco, la mayor empresa de trabajo temporal, y de Citigroup, una de sus accionistas. Los políticos que pretenden seguir manteniendo un estatus de millonarios tras su jubilación política saben que las grandes corporaciones son la vía para poder mantener los privilegios que acompañan al poder una vez terminados sus mandatos. No cuesta adivinar que para ser fichados después hay que hacer favores antes

\section{Conclusiones y bases para otra Europa}

Que el voto en las elecciones europeas sirva sólo para orientar al Consejo Europeo en la elección del presidente de la Comisión resulta democráticamente muy insuficiente. Los ciudadanos europeos debiéramos poder elegir un gobierno europeo a través de unas elecciones europeas, o cambiar la orientación de ese gobierno mediante votación, tal y como sucede en las unidades políticas democráticas cuando se celebran elecciones. Quienes no desean una democracia en la UE recurren a la metáfora del OPNI delorsiano para justificar el marco post-democrático en el que convivimos dentro de la UE. Los europeos, vienen a argumentar, debemos aceptar - sine die-que en la UE no se dan las condiciones para establecer una democracia parlamentaria y confiar en que algún día los Estados nacionales y los pueblos europeos estén preparados para diluirse en el marco de una federación europea democrática. Así, que no queda, en nombre del europeísmo, que ser pacientes y aceptar lo que tenemos. Esta formula de integración para-democrática que forma parte del credo europeísta no solo lleva años perdiendo apoyos entre la población europea, sino que está sirviendo para des-demo- 
cratizar a los Estados Miembros. Una mayoría de las reformas planteadas desde hace décadas para democratizar la UE han quedado en nada ${ }^{56}$. La UE se parece cada vez más a un sueño oligárquico, en donde tampoco existen medios de comunicación europeos: televisiones, radios, periódicos y publicaciones, capaces de configurar una opinión pública que informe y sirva de control frente al poder de sus instituciones. No hay duda de que Europa debe afrontar con urgencia el desplazamiento del eje mundial hacia Asia y el Pacífico, y que en consecuencia tiene que reforzar los lazos comerciales y culturales con América, así como emprender una política de desarrollo en África, ya contemplada en la Declaración Schuman.. Pero para poder fortalecer su posición en el mundo y favorecer el bienestar de sus ciudadanos y vecinos, Europa, debe a mi juicio, cambiar su estructura institucional y su orientación política. En mi opinión, o la UE se democratiza y defiende un mercado social europeo o de proseguir con su orientación liberal seguirá alimentando su desintegración ${ }^{57}$.

Las candidaturas de Juncker y Schultz a la presidencia de la Comisión Europea dieron lugar a un animado debate entre el otrora presidente del eurogrupo con el del Europarlamento. Con la sucesiva elección de uno y de otro a las presidencias de la Comisión y del Parlamento, compartiendo apoyos recíprocos, se ha vuelto a demostrar que ambos son la cara y la cruz de una misma y desgastada moneda. La Gran Coalición que dirige las instituciones europeas al tiempo que da muestras de su inanidad en la crisis de Ucrania, como ante las dramáticas solicitudes de refugio de miles de desamparados por las guerras en las fronteras de Europa, sigue ofreciendo un refugio seguro para las corporaciones multinacionales. Al mismo tiempo que la UE dice apostar por el medio ambiente y el empleo, consiente el desmantelamiento industrial y la comercialización en Europa de productos fabricados en condiciones laborales y medioambientales horrendas cuyos astronómicos beneficios apenas tributan. Esas mismas cadenas y grandes firmas van expulsando del mercado a sus competidores locales hasta convertir los centros de las ciudades europeas en un mismo «no lugar».

Hacer frente al avance de la oligarquización y al declive de los Estados-nación implica un poder europeo dotado de instituciones y recursos que no dependan de delegados de los Estados Miembros que como el Consejo Europeo o el Consejo de Ministros de la UE actúan en buena medida

56 Como las propuestas de reforma planteadas por Schmitter a comienzos del milenio. Schmitter, Philippe C. 2000. Come democratizzare l'Unione europea e perché. Bologna: il Mulino.

57 MAESTRO BUELGA, G., «Del Estado social a la forma global de mercado», Constitucionalismo Crítico, op.cit., 2015, pp. 53-94. 
al servicio de círculos oligárquicos. No se trata de que Europa la dirija un directorio autocrático sino un órgano de gobierno democrático. Por eso, el ejecutivo europeo debería federalizarse y responder a una legitimidad democrática que pudiera ser parlamentaria, como en Alemania o Canadá, o como en EEUU o Brasil presidencialista, o según un sistema mixto como en Francia o Argentina. En todo caso, la ciudadanía debiera poder mediante unas elecciones europeas elegir o cambiar la orientación política del gobierno europeo. Una parte de los diputados de su parlamento podrían elegirse en circunscripciones territoriales y otros conforme a listas europeas comunes. Por otro lado, dar un carácter social de la Unión implicaría orientar sus políticas al empleo de sus ciudadanos y no solo a mantener la estabilidad de los precios. Cubrir con un seguro de desempleo europeo a los parados sería un recurso que aliviaría el descrédito de la UE entre las clases populares y que actuaría como medida de corrección sobre las asimetrías de la eurozona. La Unión debería establecer garantías para impedir que los abusos productivos extramuri redundaran en el traslado de la producción fuera de Europa. Una consecuencia inevitable si en China la hora de trabajo en jornadas de 10 horas y seis días a la semana se paga a 0.5 euros y en Bangladesh o Vietnam no supera los 0.12 céntimos. Siguiendo una simple lógica economicista el desmantelamiento industrial europeo y el traslado masivo de servicios a Asia no cesará de aumentar, salvo que se asiatizen los mercados europeos, una orientación a la que parece apuntar la creciente precarización de sueldos y salarios en la UE.

Las consecuencias de las políticas neoliberales que desde la UE se promueven para sus Estados miembros están resultando catastróficas para el modelo de bienestar europeo. Además, están dando impulso a fuerzas políticas opuestas a la integración. La globalización neoliberal también tiene un efecto esquilmatorio sobre los ingresos de las arcas públicas dado que la conexión entre las corporaciones multinacionales, los paraísos fiscales, el fraude y la elusión fiscal es muy intensa. De hecho, los grandes beneficiarios de la globalización apenas contribuyen fiscalmente. A través de un entramado internacional de «ingeniería de matrices» las grandes corporaciones aportan menos del 1\% de sus ingresos. Resulta urgente una nueva política fiscal europea que acometa la existencia de paraísos fiscales. Pero una nueva Europa también requiere de una red educativa que destine mayores recursos a la formación y al intercambio. Hay que universalizar programas como Erasmus, en lugar de cómo acontece, disminuir sus recursos. También hacen falta redes comunicativas que contribuyan a configurar una opinión pública. Europa debe emprender nuevas políticas laborales en defensa del empleo y de la dignidad salarial; y aumentar sus recursos presupuestarios para desarrollarse socialmente; o establecer una nueva fiscalidad frente a las grandes corporaciones y las transacciones financieras. En mi 
opinión, o Europa da pasos urgentes hacia una federación democrática y social o las democracias estatales y la UE pueden quedar reducidas en breve a un decorado institucional. No solo se trata de democratizar la integración continental; si no se democratiza la UE también está en juego, el futuro de las democracias en los Estados Miembros.

La UE, al renunciar a su defensa en favor de la OTAN ha optado por ser en el siglo XXI un compañero de viaje del aventurismo americano. Las desestabilizaciones promovidas en el mundo árabe, o en Ucrania, afectan por proximidad de una manera muy intensa a Europa. El respaldo a la administración de W.Bush en la ocupación de Afganistán e Irak, o los efectos de las desestabilizaciones en Libia y Siria, han convertido a la UE en un territorio más vulnerable que antes. Además, el apoyo de las instituciones europeas a las sucesivas intervenciones en el mundo árabe han propiciado una alienación creciente entre la población musulmana «extra et intra muros» que mayoritariamente las percibe como agresiones de carácter imperialista. El recurso sistemático a la violencia como paradigma de una estrategia político-militar, característico de EE.UU. no puede ser también el de la UE, que carece de un ejercito europeo. Por otro lado, la pretensión de la UE de ser una referencia de los derechos humanos y de la democracia en el mundo resulta a menudo contradictoria. Un ejemplo de la hipocresía europea es su actitud ante el último caso de descolonización: el Sahara Occidental. Como ha puesto en evidencia la reciente sentencia del TJUE ${ }^{58}$ que ha invalidado el acuerdo de libre comercio entre la UE y Marruecos, los gobiernos de la UE, representados en el Consejo, no tomaron en consideración los intereses de la población saharaui en los territorios ocupados por Marruecos, ignorando la legalidad internacional que contradice los intereses coloniales marroquíes. La cuestión del Sahara Occidental puede servir como una prueba del algodón para valorar la auténtica voluntad de la UE por extender la democracia en el mundo. Ese objetivo, de ser real, implicaría una preocupación por las condiciones de vida de la población saharaui, tanto en los territorios ocupados, como de la que sobreviven en campos de refugiados en el desierto argelino desde hace cuatro décadas ${ }^{59}$. La UE debería respetar las decisiones de Tribunales internacionales que como el de

58 Sentencia contra la decisión del Consejo 497/2012 de 8 de marzo, fundamento de los acuerdos comerciales entre la UE y Marruecos suscritos en aquel año. La sentencia, asunto T 512/12 de 10 de diciembre de 2015 está disponible en: http://curia.europa.eu/juris/document/ document.jsf?text\&docid=172870\&pageIndex=0\&doclang=FR\&mode=req\&dir\&occ=first \& part $=1 \&$ cid $=232980$.

59 Una recopilación de la memoria histórica de cientos de violaciones a los derechos de la población saharaui están recogidos en el estudio de: MARTIN BERISTAIN, C. y GONZÁLEZ HIDALGO, E., El oasis de la memoria. 2 Tomos. Bilbao: EHU-UPV y Hegoa, 2012. 
la Haya declaró en 1975 que la cesión de soberanía española a Marruecos y Mauritania no tenía fundamento legal. La suscripción del acuerdo con Marruecos desinteresándose de la suerte de la población autóctona lo interpretaba - correctamente - el Tribunal de Luxemburgo como un gesto de apoyo a la ocupación ${ }^{60}$.

Para la clase media europea las últimas décadas han supuesto un estancamiento y las rentas en la base de la pirámide aún han ido a peor. La desigualdad social ha aumentado. Se ha dado un aumento escandaloso de beneficios y una concentración de rentas y patrimonio en lo que se denomina el $1 \%$. En realidad, en el $0,1 \%$, en unas proporciones que no tienen precedentes históricos. Esa acumulación ha propiciado una captura del poder político que a su vez ha favorecido una ulterior acaparación de rentas. Sin embargo, no cabe decir que la tarta haya aumentado de tamaño. Más bien, se ha concentrado en favor del sector más privilegiado acosta de todos los demás. De hecho, el crecimiento económico en occidente ha sido más estadístico que real, vinculado a las burbujas bursátiles e inmobiliarias, que al estallar han conducido a una crisis sin parangón en casi cien años y a un retroceso en décadas. Además, las medidas de austeridad adoptadas en Europa han agudizado el declive, en particular de los Estados más débiles de la zona euro que han sido conducidos a una profunda recesión. El desempleo ha aumentado hasta niveles desconocidos, como también la precarización del trabajo y de los salarios, salvo para la franja del $1 \%$ que recibe rendimientos anuales de seis cifras anuales en dólares o euros, y muy en especial para el $0,1 \%$ de «überich»o superricos que se han hecho con un patrimonio digno de las 1001 noches.

Esa inmensa y creciente desigualdad es un potente freno al crecimiento. La concentración de rentas y patrimonio en unos pocos, frena el consumo de la mayoría. Esa acumulación también precariza la democracia y el Estado de derecho. Pero no se trata de unas consecuencias de mercado inevitables, sino de decisiones económicas y políticas adoptadas por sedes institucionales. Aunque la desigualdad se ha convertido en una cuestión muy relevante de la globalización, se postergan las medidas para corregir sus efectos ${ }^{61}$. Sin embargo, es posible adoptar medidas que hagan disminuir o ralentizar el crecimiento de las desigualdades, lo que implicaría adop-

${ }^{60}$ En particular los puntos 217 a 247 de la sentencia. Los productos del expolio saharaui que se comercializan como marroquíes forman parte del círculo de empresas pertenecientes al soberano alauita «Les Domaines» que posee grandes plantaciones e invernaderos en el territorio ocupado, en concreto en los alrededores de Dajla. Vid., http://www.wsrw. org/a1 10x3338.

${ }^{61}$ Una seria advertencia sobre las consecuencias y una colección de remedios en STIGLITZ, J.E., La Gran Brecha. Barcelona: Taurus, 2015. 
tar nuevas normas de gobernanza que impiden los abusos y fraudes de ingeniería financiera o el acaparamiento de enormes beneficios empresariales en favor de algunos directivos corporativos. También serían necesarias nuevas políticas fiscales que dejen de hacer posible que las rentas de capital sean gravadas muy por debajo de las rentas salariales provenientes del trabajo. La fiscalidad debe favorecer a quien crea empleo o mejore el medio ambiente y debe gravar especialmente a quien se enriquece especulando o contaminando. El aumento de los ingresos fiscales debe dirigirse a inversiones en enseñanza, investigación e infraestructuras. También se debe poner freno al acaparamiento de rentas a través de exenciones, ayudas y beneficios ligados al clientelismo. Para evitarlo, deben limitarse las donaciones políticas a fundaciones o las condonaciones de deudas bancarias a los partidos políticos.

Por el contrario, en lugar de ese tipo de medidas, a través del BCE o de la Comisión Europea, del Eurogrupo o del FMI y desde un conjunto de instituciones no mayoritarias o de un ramillete de organismos vinculados a ellas, se ha exigido a los Estados que impongan una política económica caracterizada por los recortes sociales y la contracción de la demanda. Para cumplir ese objetivo se ha puenteado la voluntad de los electorados nacionales, supeditados a seguir las directrices de un marco económico decidido de antemano. El resultado no es sólo un debilitamiento democrático. Además y sin excepción, los resultados de la aplicación de la ortodoxia neoliberal ha conducido a una recesión o incluso a una aguda y prolongada depresión económica. Así, las diferencias entre las fuerzas políticas en lo que se refiere a la orientación de sus políticas económicas no parecen muy significativas entre las siete unidades políticas más importantes del Planeta: UE, EEUU, Japón, Rusia, China, Canadá y Brasil que concentran cerca de la mitad de la población mundial y el $80 \%$ del PIB. Ya se trate del partido comunista chino, los republicanos y demócratas de EEUU, el partido de los trabajadores brasileiro, el nuevo laborismo, el partido popular europeo o los conservadores canadienses, unos y otros coinciden en el impulso a un neoliberalismo que sólo difiere en la forma de aplicación. Mientras que unos lo prefieren disciplinario otros lo prefieren compensatorio. Las diferencias son más de forma que de fondo y las discrepancias son relativas a intereses nacionales y corporativos.

La globalización se conduce mediante un modelo común de capitalismo financiarizado que tiene como objetivo la revisión del modelo de constitucionalismo social y democrático. Mediante reformas y mutaciones que alteran la constitución material de postguerra común a los Estados Miembros, los tratados europeos han convertido la centralidad del mercado en un paradigma incuestionable. La constitución económica de la UE ha relegado lo social a un campo adscrito al marco competencial de los es- 
tados miembros pero subordinados a los nuevos poderes «comunitarios» ${ }^{62}$. El derecho europeo está afectando a la elaboración democrática de las fuentes o al control de la acción política al debilitar los efectos de las elecciones. No sólo no hay una constitucionalización del proceso de integración sino que al mismo tiempo se están desconstitucionalizando los ordenes estatales ${ }^{63}$.

La plutocracia o el poder del dinero, está conduciendo a un crecimiento débil y excluyente. El objetivo de una sociedad más igualitaria se topa con los obstáculos de quienes se oponen a limitar la riqueza y la influencia de intereses que sólo aspiran a obtener más privilegios. La reducción de impuestos a favor de quienes más tienen no ha conducido a un reparto de beneficios. La política de goteo propagada por las tesis neoliberales se ha demostrado una inmensa falacia. Por el contrario, las tesis y políticas neoliberales han facilitado una acumulación desorbitada a favor de muy pocos. Desde la crisis de 2007 el 1\% se ha quedado con más del $90 \%$ de los beneficios y la austeridad ha provocado una recuperación sin empleo o una precariedad de bajísima calidad. La mayoría de los nuevos trabajadores han sido condenados a una vida de penuria, es decir: a trabajar para ser pobres. Ni los más optimistas y despreocupados pueden negar que la democracia se ha mercantilizado y corrompido y que hoy se gobierna fundamentalmente de cara a los intereses de quienes viven en el vértice de la pirámide. Desde las tesis oligárquicas se defiende que la globalización beneficia al conjunto y que la nación o el Estado salen ganando con ella. Lo cierto es que para la mayoría este modelo de globalización resulta perjudicial. Incluso para los cientos de millones que en China o en Brasil han abandonado la pobreza rural, las condiciones laborales y de vida en las ciudades son cada vez más difíciles. Sólo para las grandes corporaciones y sus aliados, aporta la globalización grandes beneficios, dado que el acceso a mano de obra y bienes en todo el mundo o su capacidad de venta «über alles» proporciona ganancias colosales. Además, esa ubicuidad se transforma a su vez en invisibilidad fiscal. Porque a través de los paraísos y de la ingeniería fiscal la contribución de esos grupos a las sociedades que les procuran esos beneficios fabulosos es reducidísima.

La crisis griega, cuyo desenlace sigue siendo impredecible, debería haber servido de revulsivo democrático al proceso de integración. Sin embargo, en su penosa gestión ha puesto en evidencia el abrumador dominio de Alemania sobre el resto de Estados y ha servido para demostrar la falta

62 DE CABO MARTIN, C., «Constitucionalismo del Estado social y Unión Europea en el contexto globalizador», Revista de derecho constitucional europeo, n. . 11, 2009, pp. 17-48.

63 BALAGUER, F., «Crisis Económica y crisis constitucional en Europa», Revista Española de Derecho Constitucional, n. ${ }^{\circ}$ 98, 2013, pp. 91-107. 
de controles democráticos de la ciudadanía europea sobre el entramado institucional de la UE. Así, nos hemos enterado de que el Eurogrupo es una asociación informal sin reglas escritas. Esa fue precisamente la respuesta de su Secretaría jurídica cuando el gobierno griego objetó no haber sido convocado por su presidente a una de sus reuniones ${ }^{64}$. Aunque en su seno se adopten decisiones de la máxima relevancia para la política económica de sus estados miembros y la vida de sus ciudadanos, el Eurogrupo es una organización legalmente inaprensible que orbita más allá del control de sus miembros ... Esa configuración anómica representa un paso más en el desarrollo de la UE como modelo postdemocrático en una suerte de democracia hayekiana muy alejada de sus orígenes griegos. No está de más recordar que la democracia clásica de Pericles se fundaba en la selección por insaculación. En la Europa del siglo XXI la selección cada vez más remota de sus representantes como método de participación y el papel aleatorio del Parlamento Europeo en la toma de decisiones sobre política-económica son una burla democrática plenamente institucionalizada. Sólo y a posteriori, tras el referéndum griego, se ha convocado a los parlamentos de la eurozona para ratificar «el tercer rescate». Los dos anteriores, así como otras decisiones, como la del crédito puente de julio de 2014, se adoptaron, como es costumbre, al margen de controles y debates parlamentarios.

La crisis griega pone de manifiesto graves irresponsabilidades e irregularidades tanto de Grecia como de las instituciones europeas, así como un comportamiento temerario y escandaloso de las corporaciones financieras $^{65}$. Pero el euro ha permitido que Alemania sea mucho más competitiva. Se calcula que de haber mantenido el marco este valdría hoy entre dos y tres veces más. En esas condiciones, las posibilidades germanas de penetrar en otros mercados hubieran sido mucho menores. Como resulta evidente, la zona euro adolece de grandes asimetrías y fue mal diseñada, sin haberse previsto instrumentos de corrección y salvaguarda. Como la crisis ha puesto de manifiesto una y otra vez, se ha recurrido sistemáticamente a la improvisación, adoptando medidas insuficientes que luego eran corregidas y completadas cada poco tiempo. La falta de una reserva o de un tesoro

64 Vid. Declaraciones de Varoufakis sobre su experiencia en el Eurogrupo recogidas en Le Monde Diplomatique 238/2015, pp. 20-21.

65 A finales de los noventa el Gobierno de Kostas Simitis pagó 300 millones de euros a Goldman-Sachs por un estudio que encubría una gigantesca falsificación estadística y Grecia, que no cumplía con la mayoría de los criterios de Maastricht, pudo incorporarse en 2004 a la eurozona. Casualmente el entonces vicepresidente europeo de Goldman-Sachs es el actual presidente del Banco Central Europeo, Mario Draghi. Vid., KOUVELAKIS, S., «El crisol griego», New Left Review, 72, 2012, pp. 15-29. 
europeo ha perjudicado a las economías más débiles, incapaces de contener la especulación sobre sus deudas públicas. La falta de una unión fiscal que requeriría de una unión política plantea un incierto futuro a la unión monetaria realmente existente. Como finalmente ha reconocido el FMI la deuda griega resulta a todas luces impagable dado que Grecia necesitaría superávits primarios de cerca del $7 \%$ durante más de un decenio. Una perspectiva fuera de la realidad. Sin embargo, sistemáticamente, el eurogrupo se ha negado a una quita o a reestructurarla dulcificando las condiciones y plazos de pago, es decir aceptando una moratoria, tal como reclamaba el Gobierno griego para poder encarar con cierto margen de tiempo los necesarios cambios presupuestarios o fiscales. Pero a pesar de las disparatadas condiciones de los rescates, a todas luces ineficaces dado que la deuda pública ha escalado hasta el $180 \%$ del PIB, se ha vendido ante la opinión pública su idoneidad recurriendo a diversas cantinelas. Se ha difundido la idea de que los griegos son vagos y corruptos, incapaces de organizar eficazmente su Administración y economía. De ahí se extraía la conclusión de que las medidas de la Troika avaladas por el modelo de eficiencia y organización de Alemania estaban justificadas. También por un criterio moral que exige que las deudas sean pagadas. Poco importa que Grecia condonara a Alemania las reparaciones por los crímenes nazis, como también hicieron otros países europeos en la conferencia de Londres de 1953 en relación al 62\% de la deuda alemana. Alemania parece considerar desde hace años el proceso de integración como un instrumento para configurar una Europa alemana. La actitud tanto de Merkel o de su poderoso ministro de Finanzas, Schauble, arropados por los medios de comunicación, es un ejemplo de arrogancia. Hacen eco a un artículo en una revista alemana de predicamento entre las élites políticas y económicas, Merkur, donde se defendía que el papel de Alemania en Europa debía ser similar al de Prusia en el Reich y que Francia debía ser tratada como entonces lo fue Baviera por Bismarck. Conforme a esa visión, cabe preguntar ¿qué trato les esperaría a los estados más débiles y pequeños?

La oligarquización democrática es un oxímoron teórico pero sin embargo un proceso político, a mi entender, muy real, que promueve un trasvase de poder a instituciones no mayoritarias que viene acompañado de unas políticas de redistribución invertidas. A golpe de crisis se malvenden los activos públicos a las grandes corporaciones y fondos de inversión internacionales; se bajan impuestos en los tramos más altos a los más pudientes, o se reprimen los salarios de los trabajadores menos cualificados. Medidas que forman parte del credo neoliberal que orienta la política económica que se impone desde la UE con la connivencia de los poderes dominantes en los Estados Miembros. En el marco de la UE, los tratados comunitarios se han convertido en instrumentos para la desconstitucionalización de los ordenes 
políticos estatales ${ }^{66}$. Cuando la reforma comunitaria plantea dificultades es habitual recurrir a suscribir tratados internacionales que alteran los ordenes internos de los Estados Miembros. El europeísmo debe concluir su connivencia con semejante proyecto neoliberal cuyo objetivo es extender la oligarquización a la UE y a todo el Planeta. Para quienes la sociedad no existe (Thatcher dixit) o es básicamente un marco de oportunidades para hacer negocio, la integración europea debe ser sobre todo un experimento postdemocrático. A pesar de la retórica innovativa, la globalización es un recurso para promover como los viejos principios rectores de la oligarquía: la desigualdad y la concentración de poderes ${ }^{67}$. La justificación del lujo y de la miseria «über alles» conduce al apocalipsis de las clases medias europeas que siguen la senda de declive por la que transitan en EE.UU. en tanto que jinete que encabeza ese modelo globalizador ${ }^{68}$.

Las propuestas para una representación sin contenido o una decisión sin elección sirven a la legitimación neoliberal del mercado. En oposición al constitucionalismo social, el neoliberalismo impulsa una nueva relación de fuerzas entre Capital y Trabajo. Como entre nosotros se ha puesto de manifiesto con ocasión del escandalo de Euskaltel ${ }^{69}$, las privatizaciones, despidos y externalizaciones, la precarización y la falsa valoración de activos en beneficio de directivos, gestores de fondos y accionistas caracteriza a un capitalismo de fondos de inversión. Mientras Wall Mart con 1.200.000 trabajadores en nómina es la empresa con más empleados del mundo occidental y su familia propietaria de las más ricas del Planeta, más del 50\% de sus empleados necesita de ayudas públicas para llegar a fin de mes. Como lógica de acumulación y poder el capitalismo presenta una simplificación del mundo, como si todo fuera un asunto económico en donde el individuo está solo, librado a su suerte y destino, sometido a una ley que tiene que obedecer. En lugar de políticas de pleno empleo la UE ha favorecido la precarización de empleo y salarios, el debilitamiento de la sindicación y la marginación de los convenios laborales, una fiscalidad favorable a las rentas de

${ }^{66}$ Un conjunto de reflexiones sobre democracia, legitimidad y justicia en: CHAMPEAU, S., CLOSA, C., INNERARITY, D., and POIARES MADURO, M., (eds.), The future of Europe. London: Rowman\&Littlefield, 2015.

67 Una reflexión crítica sobre las crecientes desigualdades en STIGLITZ, J.E., La Gran Brecha. Barcelona: Taurus, 2015.

${ }^{68}$ Una extensa red de datos sobre el papel militar de EE.UU. en: DEBRAY, R., «¿La decadencia de Occidente?», New Left Review 80, 2013, pp. 31-48. Una impresionante recapitulación del sistema electoral americano en: DAVIS, M., «¿Las últimas elecciones blancas?», New Left Review 80, 2013, pp. 7-60. Una detallada exposición de sus políticas en: ANDERSON, P., «Homeland. La política interna de Estados Unidos», New Left Review 81, 2013, pp. 7-37.

69 Vid., diario El Mundo de 24/06/2015. 
capital y balances presupuestarios dependientes del consumo o benefactores de mecanismos fiscales de elusión. A mantener paraísos fiscales o a que Warren Buffet cotice menos que su secretaria. A abandonar el paradigma de un Estado Social donde los poderes públicos procuran vivienda, sanidad, educación y trabajo en el marco de un capitalismo distributivo y decente, en favor de un paradigma neoliberal de capitalismo salvaje. A marginar un capitalismo industrial por otro de especulación donde priman los productos de ingeniería financiera. A encumbrar un nuevo paradigma moral de antiguo testamento con sus triunfadores, lujo, avaricia, codicia y corrupción. Una distopía social de ganancias privadas y socialización de perdidas ${ }^{70}$.

Ante ese panorama, el auge del euroescepticismo representa un escapismo político que no tiene en consideración las exiguas dimensiones de los Estados europeos. Según la prospectiva, en 2035 ningún Estado europeo, ni tan siquiera Alemania, formaría parte de un G-7. En el plazo de la próxima generación la existencia de unidades políticas de las dimensiones de EEUU, China, India, Brasil, Japón, Rusia o Indonesia, exige a los europeos dar pasos, no de vuelta al Estado-nación, sino hacia una unidad federal. Un objetivo que los defensores del Estado nacional no quieren alcanzar. Aunque se presentan como europeístas los defensores del Estado-nación en el marco de la UE son más bien fuerzas que tratan de mantener al Estado como fundamento de la integración, limitando el avance de la europeización y debilitando democráticamente al Estado. Sin embargo, la Unión Europea requiere de nuevos recursos institucionales, comunicativos, presupuestarios y financieros propios. Frente a euroescépticos y europeizantes hace falta fortalecer y federalizar la UE. Una transformación ${ }^{71}$ que debiera venir acompañada de su democratización y del impulso de una economía social de mercado ${ }^{72}$, es decir, alejarse del paradigma neoliberal que orienta desde hace años a las instituciones europeas. La UE no sólo es una fuente de problemas sino también un proyecto de solución. De momento su desequilibrio dinámico y la falta de un objetivo preciso se han convertido en recursos que paradójicamente mantienen a flote el proceso de integración. Pero una precariedad que a falta de una legitimidad democrática y de resultados proyecta una amenazadora sombra sobre su futuro.

El coste de no haber hecho de la UE una federación democrática es una estructura oligarquizada que ha debilitado la democracia. A la política sin democracia de la UE se ha sumado, a medida que aumentaban los pode-

70 BARCELlONA, P., Il suicidio dell'Europa. Dalla coscienza infelice all'edonismo cognitivo, Bari: Dedalo, 2005.

71 BARTOLINI, S., Restructuring Europe, Oxford: UP, 2005.

72 Un Estado social para el siglo XXI es una de las propuestas del monumental estudio de: PIKETTY, T., El Capital en el siglo XXI. Madrid: Fondo de Cultura Económica, 2014. 
res comunitarios, una democracia sin política en los Estados Miembros. El sueño de la burguesía europea de una sociedad despolitizada y gestionada por una tecnocracia funcionó mientras la integración procuró bienestar a una gran clase media. Pero con la deriva neoliberal de la globalización la posición de la clase media europea se ha precarizado y su creciente desconfianza en la tecnocracia ha conducido a una crisis de legitimidad tan aguda que parece difícil que los arreglos reformistas característicos del funcionalismo puedan servir como remedio. Tal vez Europa perdió durante la última década el tren de la integración y el tiempo ya juegue en su contra. $\mathrm{O}$ tal vez, el malestar de la UE transformada en una distopía social y democrática de lugar a una reacción popular que exija avanzar hacia una federación europea democrática y social. De momento, como en el Fausto de Goethe, dependemos de las criaturas que hemos creado. Una dependencia distópica que espero no resulte definitiva ${ }^{73}$.

73 «Am Ende hängen wir doch ab Von Kreaturen, die wir machten». Mephistofeles al público desde el laboratorio en el II acto del Fausto. En el original alemán la dependencia - Am Ende- parece definitiva. 


\section{Derechos de autor (Copyright)}

Los derechos de autor de esta publicación pertenecen a la editorial Universidad de Deusto. El acceso al contenido digital de cualquier número de Cuadernos Europeos de Deusto (CED) es gratuito, transcurridos 6 meses desde su publicación. Los trabajos podrán descargarse, copiar y difundir, sin fines comerciales y según lo previsto por la ley. Así mismo, los trabajos editados en CED pueden ser publicados con posterioridad en otros medios o revistas, siempre que el autor indique con claridad y en la primera nota a pie de página que el trabajo se publicó por primera vez en CED, con indicación del número, año, páginas y DOI (si procede). 